NBER WORKING PAPER SERIES

\title{
BROKERS AND ORDER FLOW LEAKAGE: EVIDENCE FROM FIRE SALES
}

\author{
Andrea Barbon \\ Marco Di Maggio \\ Francesco Franzoni \\ Augustin Landier \\ Working Paper 24089 \\ http://www.nber.org/papers/w24089 \\ NATIONAL BUREAU OF ECONOMIC RESEARCH \\ 1050 Massachusetts Avenue \\ Cambridge, MA 02138 \\ November 2017
}

We thank Malcolm Baker, John Campbell, Laurent Frésard, Slava Fos (discussant), Gary Gorton, Owen Lamont, Jongsub Lee (discussant), Andrew Lo, Toby Moskowitz, Erik Stafford, and seminar participants at the Becker Friedman Institute CITE conference on New Quantitative Models of Financial Markets, FINRA Market Structure conference, LAEF 2nd OTC Markets and Securities Workshop, and AQR for helpful comments. The views expressed herein are those of the authors and do not necessarily reflect the views of the National Bureau of Economic Research.

At least one co-author has disclosed a financial relationship of potential relevance for this research. Further information is available online at http://www.nber.org/papers/w24089.ack

NBER working papers are circulated for discussion and comment purposes. They have not been peer-reviewed or been subject to the review by the NBER Board of Directors that accompanies official NBER publications.

(C) 2017 by Andrea Barbon, Marco Di Maggio, Francesco Franzoni, and Augustin Landier. All rights reserved. Short sections of text, not to exceed two paragraphs, may be quoted without explicit permission provided that full credit, including $\odot$ notice, is given to the source. 
Brokers and Order Flow Leakage: Evidence from Fire Sales

Andrea Barbon, Marco Di Maggio, Francesco Franzoni, and Augustin Landier

NBER Working Paper No. 24089

November 2017

JEL No. G12,G14,G23,G33

\begin{abstract}
$\underline{\text { ABSTRACT }}$
Using trade-level data, we study whether brokers play a role in spreading order flow information. We focus on large portfolio liquidations, which result in temporary drops in stock prices, and identify the brokers that intermediate these trades. We show that these brokers' best clients tend to predate on the liquidating funds: at the beginning of the fire sale, they sell their holdings in the liquidated stocks, to then cover their positions once asset prices start recovering. The predatory trades generate at least 50 basis points over ten days and cause the liquidation costs for the distressed fund to almost double. These results suggest a role of brokers in fostering predatory behavior and raise a red flag for regulators. Moreover, our findings highlight the trade-off between slow execution and potential information leakage in the decision of optimal trading speed.
\end{abstract}

Andrea Barbon

Universita' Svizzera Italiana

andrea.barbon@usi.ch

Marco Di Maggio

Harvard Business School

Baker Library 265

Soldiers Field

Boston, MA 02163

and NBER

mdimaggio@hbs.edu
Francesco Franzoni

Swiss Finance Institute

Via G. Buffi 13

6904, Lugano - Switzerland

and University of Lugano

francesco.franzoni@usi.ch

Augustin Landier

the Toulouse School of Economics

21 Allée de Brienne

31000 Toulouse, FRANCE

augustin.landier@tse-fr.eu 


\section{Introduction}

Large institutional orders are typically split in smaller amounts over time to avoid market-impact (see Garleanu and Pedersen, 2013, Di Mascio et al., 2016). One concern when executing an order slowly over time is that other traders might anticipate the intent to trade the stock in the near future and take advantage by trading in the same direction to benefit from the future price impact. Predatory trading has strong theoretical support (Brunnermeier and Pedersen, 2005) and is borne out by anecdotal evidence. For example, during the unwinding of LTCM's portfolio in 1998, the fund's typical trading and lending counterparties, which were privy to its portfolio positions, also sold the same assets. Given that predatory trading can make the market more illiquid at times of crisis and amplify adverse shocks, some observers suggest that reducing the frequency of portfolio disclosure can be desirable (Brunnermeier and Pedersen, 2005). Accordingly, hedge funds support regulations that limit the granularity of their reporting (IAFE, 2001).

One wonders, however, if restricting the diffusion of public information is a sufficient measure to prevent predatory behavior. In fact, the anecdotal evidence mentioned above suggests that market participants possess information about forced liquidations thanks to their close relationship with the liquidating managers. Among all actors in the market, brokers are in the privileged position of observing the daily trades of a fund. In the case of hedge funds, prime brokers operate also as lenders and risk managers, so that they are aware whether the fund is about to breach some risk limit and deleverage its portfolio. They can also observe the trading habits of their clients, such as whether they tend to cut trades in small orders over several days when executing a large order. In sum, brokers are in a privileged position to predict the future trades of their clients.

Brokers may decide to spread the news that a client's large trade is likely to extend over several days to other traders. They may have an incentive to do so in order to establish a reputation as a source of valuable information and attract new business. On the other hand, brokers may care about the long-term relationship with their clients. Hence, brokers may be reluctant to foster predatory trading against a client. Rather, according to this argument, they should invite other traders to provide liquidity and take the other side of the slow trade. It remains, therefore, an open empirical

question whether brokers foster predatory trading or liquidity provision in case of slow trading by a client. The paper aims to address this question. 
Forced liquidations of portfolio holdings offer an ideal setting to investigate these issues. Other traders, if made aware of the liquidation, can exploit these opportunities to sell the same assets in anticipation of the price drop and reverse the trade once the price has fallen. This opportunistic behavior makes liquidations more costly for the liquidating manager because it exacerbates the adverse price move. We decide to focus on large liquidations (which we label "fire sales" for convenience), and do not include large purchases in our analysis, because we aim to have a clean identification of liquidity-motivated trades. First, in our data, the majority of institutional investors are long-only (about 90\%). Hence, it is somewhat less likely for a sale to be information motivated (as the manager would need to have the stock already in the portfolio) than for a buy transaction. Second, large cash inflows can be allocated slowly over time and are, therefore, less likely to impose a concentrated liquidity demand on the market than large outflows.

Specifically, we exploit proprietary trade-level data and focus on asset managers that sell a significant fraction of their portfolio during a relatively short amount of time. We restrict attention to asset managers whose order flow is abnormally negative for at least five days in a row. Moreover, we focus on managers that liquidate multiple stocks (on average about 20 stocks) at a significantly faster pace than usual. We identify about four hundred of these events in the period between 1999 and 2014. Because we are only interested in fire sales due to purely liquidity motives, such as the need to meet large redemptions, we verify that the stock price movements resulting from this sale are only temporary and that the asset managers do not buy back those stocks. Price impact would have to display a permanent component, if sales were motivated by fundamental reasons. Interestingly, controlling for the portfolio weights, we show that managers are more likely to sell large, liquid, and low-volatility stocks, as well as past winners. This evidence can inform the theoretical debate on optimal liquidation policy (e.g. Scholes 2000, Brown, Carlin, and Lobo 2010).

Our empirical strategy takes advantage of two key sources of variation. First, not all brokers employed by the liquidating fund are going to be aware that the fund is in distress. The liquidating fund has little incentive to disclose its intention to liquidate a large fraction of its portfolio; in fact, it is likely to use multiple brokers to minimize price impact and info leakage. Hence, only brokers that observe a large enough fraction of the liquidation are deemed aware. Second, we should not expect all traders to predate; in fact, brokers are likely to selectively disclose the order flow information to maximize their rents. 
Our first result is that there is a significantly higher probability of predatory behavior for orders executed through aware brokers. Specifically, the clients of the aware brokers are significantly more likely to execute sell trades in the same stocks with the same broker over the same period. We also show that the clients of the aware brokers are not only more likely to sell the same stocks of the liquidating funds, but also sell a higher volume in those stocks.

Next, we explore the heterogeneity across the different clients of the aware brokers. If the brokers are spreading information about order flow, they are more likely to do so with their best clients, from which the brokers can extract the highest rents. As a proxy for the strength of the investor-broker relation, we use the trading volume and the commissions generated by a client. ${ }^{1}$ Our baseline specification focuses on an event window starting ten days before the beginning of the fire sale up to five days afterwards. We control for time, manager, event, stock, and broker fixed effects. Hence, differences across stocks, such as their liquidity, or across brokers, such as their ability to execute, cannot explain our results. ${ }^{2}$

The main result of this analysis is that the best clients of the aware brokers are significantly more likely than other clients to sell the stocks that the liquidating manager is offloading during the fire sale with respect to immediately before the fire sale. Additionally, extending the analysis to all brokers, we find this effect to be present only among aware brokers. The results are also economically significant, in fact, on average the best clients of the aware brokers are about $50 \%$ more likely to follow a predatory strategy. ${ }^{3}$

Then, we test whether the same asset managers that are predating during the fires are also likely to cover their positions by repurchasing the stock in the following days. Consistent with this hypothesis, we find that a significant fraction of their positions, ranging from $12 \%$ to $40 \%$, are covered in the ten days following the fire sale. This gives strong indication that these managers were motivated by the prospect of short-term gains at the expense of the liquidating fund.

One potential concern with our results is that fire sales might cluster in some periods and be correlated across funds. For instance, during the financial crisis most asset managers were trying

\footnotetext{
${ }^{1}$ We show that these relations are extremely persistent, consistent with the findings in Goldstein, Irvine, Kandel, and Wiener (2009), corroborating the hypothesis that brokers might have an incentive to nurture such relations.

${ }^{2}$ We also provide a specification in which we control for broker-times-manager fixed effects, which controls for the matching between asset managers and brokers. These results are in the Online Appendix.

${ }^{3}$ We also exploit the granularity of our data to corroborate our interpretation of the results by showing that the hedge funds, rather than the mutual funds or pension funds, are those for which the evidence of predation is most significant.
} 
to offload their positions in financial stocks. We address this concern in several ways. First, we show that our definition of fire sales leads to relatively short-term price reversals, rather than the prolonged asset prices swings that occurred during the crisis. In fact, our events are randomly distributed across time, showing no significant increase during the 2001 or the 2008-09 crises. Then, we also focus on events that are likely driven by funds' idiosyncratic shocks by excluding from our sample months in which there are more than five different fire sales. In addition, our results are conditional on the predators executing their orders with the same broker that is employed by the liquidating fund, while a correlated response to a common shock would predict trades that are more diffuse across brokers. The evidence, therefore, corroborates the hypothesis of a quid pro quo between investors and brokers and points out an active role of the broker in leaking the news of a fire sale. Similarly, we provide an array of additional robustness checks to rule out the possibility that the originator of the fire sale and the followers are trading as a response to the same public news. For instance, we exclude from our sample all the events that occurred during recessions and show that the results are unaffected. We also exclude all events occurring around earning announcements, changes in analyst recommendations, or any other type of negative news as reported by the press and classified by Ravenpack. ${ }^{4}$ We also exclude stocks with negative momentum and high short interest to address the concern that selling managers follow similar trading strategies founded on a negative view on the stock.

Another way to rule out the alternative hypothesis that the observed predatory trading is due to a reaction to stock-specific news is to look at the number of stocks involved in the fire sale that the best clients also sell. The idea is that if sales were motivated by stock-specific news or similar trading strategies, we should observe the best clients focusing on one or two stocks, whereas if they knew about the liquidation, it would be more profitable to prey on multiple stocks at the same time. Consistent with predatory behavior, we find that the best clients of the aware brokers are significantly more likely to sell a higher number and a higher fraction of stocks involved in the liquidation event.

To strengthen the identification of fire sale events, we focus on a natural experiment in which a few funds were forced to liquidate their holdings. Specifically, on September 3, 2003, the New York Attorney General Eliot Spitzer announced the issuance of a complaint due to the discovery

\footnotetext{
${ }^{4}$ Ravenpack is a dataset collected by analyzing financial news outlets using a machine learning algorithm to differentiate between positive and negative news about a company.
} 
of illegal late trading and market timing practices on the part of certain hedge fund and mutual fund companies. As a consequence of the scandal, twenty-seven fund families experienced significant outflows. Anton and Polk (2014) use these outflows to identify an exogenous driver of mutual funds' selling activity. Kisin (2011) estimates that funds of implicated families lost $14.1 \%$ of their capital within one year and $24.3 \%$ within two years. These outflows continued until the end of 2006. We start by matching the names of these fund families with the manager names in our trade-level dataset to identify the brokers employed by these funds to liquidate their portfolios to meet investors' redemption demands. Crucially, the brokers were aware of the specific stocks that were being sold and of the timing of these liquidations. We then show that the clients of the relevant brokers were significantly more likely to liquidate the same stocks after the scandal broke out on the same days on which the implicated funds are also selling. This test reassures us that, even when we consider plausibly exogenous variation in the source of the liquidation, we find very similar behavior.

An important question at this point, and one of the key contributions of the paper, concerns the value of the order-flow information. Recent anecdotal evidence about Citadel paying about \$100 million upfront to eTrade to receive their retail order flow would suggest that having access to this information in real time might be a very valuable piece of information. We are in a unique position to address this question by investigating whether the asset managers that receive the information from the aware brokers are able to generate higher returns. We compute the profits that these asset managers make during the fire sales and show that those who prey on the liquidating managers, e.g. the best clients of the aware broker, are able to generate between 45 and 70 bps in the few days of the fire sale, compared to the other asset managers. Given average fund performance, these results suggest that being able to predict fire sales can be quite profitable. ${ }^{5}$

We also provide evidence on the externalities arising from the previous findings, i.e. the losses incurred by managers exposed to predation. We focus on the execution shortfall, computed as the percentage difference between the execution price and a benchmark price. We find that price impact is significantly higher when the trades are executed through brokers that are aware of the large liquidation. These estimates allow us to compute the counterfactual cumulative return in a

\footnotetext{
${ }^{5}$ A placebo test in which we show that the profits of these two groups are indistinguishable in a random sample of event windows reassures us that the additional profits are indeed driven by the access to the fire sales information, and not by manager characteristics.
} 
hypothetical scenario in which none of the brokers is aware. We can then show that the transaction cost of the liquidating funds almost doubles in the presence of predatory trading.

We conclude by addressing another important question: Do brokers gain from leaking order flow information? We compute the brokers' commissions and show that the clients who take advantage of the order flow information by preying on the liquidating funds pay $10 \%-25 \%$ higher commissions after these fire sales events compared to the months before. This finding confirms that the brokers get rewarded by their clients for the order flow information they provide.

Overall, our evidence highlights and quantifies one important amplification mechanism for asset price fluctuations. Brokers can disseminate order flow information for opportunistic reasons. This behavior reinforces the price dislocations due to fire sales.

Another general implication of our findings is that there exists an important trade-off between slow trading execution meant to reduce price impact, e.g. as in Kyle (1985), and leakage of order flow information. The latter becomes more likely when the asset managers trade in the same direction over an extended period of time. This consideration is not confined to fire sales events. In fact, we find that the autocorrelation among large trades in our data is about $35 \%$. Hence, as a rule, managers tend to trade in the same direction over multiple days, which opens the possibility for the brokers to predict order flow, and for the order flow information to be disseminated from the brokers to other market participants.

Finally, our findings also have important implications for regulation. For instance, our results shed light on a recent debate over the exchanges' use of their access to market data to sell data products. The most recent dispute involves NASDAQ seeking the SEC's approval for an optionsdata service called the "Intellicator Analytic Tool." This new service would provide market color to subscribers by revealing whether a trade was initiated by a small investor or a big money manager. ${ }^{6}$ Critics maintain that pension funds and other institutional investors, who routinely need big trades to be executed anonymously, can be negatively impacted as the new service could be used to "reverse-engineer" their strategies and lead to front-running. Our findings show that, even in the absence of such supplemental information, a number of large investors, who entertain a strong business relation with brokers, are able to exploit order flow information at the expense of

\footnotetext{
${ }^{6}$ This story was reported in a recent WSJ article "Wall Street Fears Nasdaq Proposal Would Expose Trading Secrets" (available at https://www.wsj.com/articles/could-the-intellicator-spill-the-markets-secrets-1510223403?tesla=y\#comments_sector).
} 
those seeking liquidity provision. Our estimates might serve as a benchmark, and probably a lower bound, for the costs associated with releasing such data products. ${ }^{7}$

Our paper bridges two strands of the literature. First, there is a vast literature on fire sales. Theoretically, Shleifer and Vishny $(1992,1997)$ and Kiyotaki and Moore (1997) suggest that fire sales occur when the natural buyers are unable to purchase the assets due, for instance, to agency problems. However, Brunnermeier and Pedersen (2005) and Di Maggio (2016) show that the market might become illiquid exactly when liquidity is needed most due to unconstrained arbitrageurs taking advantage of the temporary price pressure by selling and then buying back the asset only after the fire sale has ended. ${ }^{8}$ Second, there is a growing number of studies investigating the importance of the network of relations among market participants in various domains, e.g. Li and Schürhoff, 2014; Di Maggio, Franzoni, Kermani, Sommavilla, 2016; Di Maggio, Kermani, and Song, 2017; Hollifield, Neklyudov, and Spatt, 2016; Afonso, Kovner, and Schoar, 2013; Hendershott, Li, Livdan, and Schürhoff, 2016. Our novel contribution is to highlight the key role played by brokers during fire sales, which might be amplified due to brokers leaking order flow information.

Our findings are also related to a growing literature examining the way in which information spreads in financial markets due, for instance, to information percolation (Duffie, Malamud, and Manso, 2009, 2014), or network effects (Babus and Kondor, 2016 and Walden, 2016). We contribute to this literature by providing empirical support to the notion that information can be readily disseminated through interactions between intermediaries and market participants. Furthermore, our results can also inform the theoretical developments of this literature as we point out that this information dissemination is strategic. In fact, the brokers selectively disclose order flow information only to some of their clients. This key feature is missing in the existing theoretical literature and might drive how networks emerge in financial markets. Also related to our paper,

\footnotetext{
${ }^{7}$ Our results also highlight the importance of the fiduciary duty between broker-dealers and their clients. A few states in the U.S. are moving in the direction of tightening such duty for brokers. For instance, Nevada is considering an expanded interpretation of fiduciary duty in which the brokers would be required to "disclose to a client, at the time advice is given, any gain [the broker] may receive, such as profit or commission, if the advice is followed."

${ }^{8}$ See Shleifer and Vishny (2011) for a survey of this literature. A complete list of works on fire sales and price dislocations in financial markets is beyond the scope of the paper, but it includes among others Allen and Gale (1994), Gromb and Vayanos (2002), Geanakoplos (2003), Lorenzoni (2008), Brunnermeier and Pedersen (2009), Acharya, Gale, and Yorulmazer (2011), Garleanu and Pedersen (2011), Stein (2012), and Diamond and Rajan (2011). Recently, Yang and Zhu (2016) provided a two-period Kyle (1985) model of "back-running," where in addition to informed and noise traders there is an investor who learns from the order-flow generated by the informed speculator after the order is filled.
} 
Farboodi and Veldkamp (2017) provide a long run growth model where traders have the option to extract information from order flow data mining and study the implication for price informativeness and market liquidity. Our results suggest that, indeed, order flow information is important in generating investors' returns and might significantly impair liquidity provision when liquidity is needed the most.

Also related to our work, the empirical paper by van Kervel and Menkveld (2016) studies the behavior of high-frequency traders (HFTs) around large institutional orders. Using Swedish data, the authors find that HFTs provide liquidity if the order is short-lived (below one hour), but they back-run on the order if it lasts for several hours within a day. The latter behavior increases the trading costs for the institution, as predicted by the theory of Yang and Zhu (2016). We find consistent evidence from a lower frequency perspective, as we analyze orders spanning multiple days. The original contribution of our work is the focus on the role of brokers in leaking the information about large institutional orders. ${ }^{9}$

The remainder of the paper is organized as follows. Section 2 describes the data sources and summary statistics and Section 3 discusses our main results on the behavior of asset managers and the role of brokers during fire sales. Section 4 presents the results on the value of order flow information, Section 5 provide further evidence to corroborate the mechanism identified in the paper, while Section 6 concludes.

\section{Data and summary statistics}

In order to analyze whether and how brokers leak order flow information during fire sales, one needs a detailed trade-level dataset that also reports information on the institutional investors and brokers involved in each trade. Abel Noser Solutions, formerly Ancerno Ltd. (we retain the name 'Ancerno' for simplicity), fittingly provides this information. Ancerno performs transaction cost analysis for institutional investors and makes these data available for academic research under the agreement of non-disclosure of institutional identity.

\footnotetext{
${ }^{9}$ Our results are also consistent with Chung and Kang (2016), who use monthly hedge fund returns to document comovement in the returns of hedge funds sharing the same prime broker.
} 
We have access to identifiers for managers that initiate the trades and brokers that intermediate those trades from 1999 to $2014 .{ }^{10}$ There are several advantages to this dataset. First, clients submit this information to obtain objective evaluations of their trading costs, and not to advertise their performance, suggesting that the data should not suffer from self-reporting bias. Furthermore, Ancerno collects trade-level information directly from hedge funds and mutual funds when these use Ancerno for transaction cost analysis. However, another source of information derives from pension funds instructing the funds they have invested in to release their trading activities to Ancerno for an independent check. Third, Ancerno is free of survivorship biases as it includes information about institutions that were reporting in the past but at some point terminated their relationship with Ancerno. Finally, the dataset is devoid of backfill bias, as Ancerno reports only the trades that are dated from the start of the client relationship.

Previous studies, such as Puckett and Yan (2011), Anand, Irvine, Puckett, and Venkataraman (2012, 2013), have shown that the characteristics of stocks traded and held by Ancerno institutions and the return performance of the trades are comparable to those in $13 \mathrm{~F}$ mandatory filings. Furthermore, Goldstein, Irvine, Kandel, and Wiener (2009), using an earlier version of our data, provide a useful description of the institutional brokerage industry. They show that institutions value long-term relations with brokers. Also, consistent with our results, the best institutional clients are compensated with the allocation of superior information around changes of analyst recommendations.

Ancerno information is organized on different layers. At the trade-level, we know: the transaction date and time at the minute precision (only for a subset of trades), the execution price; the number of shares that are traded, the side (buy or sell) and the stock CUSIP. We also know whether the trades are part of a unique ticket (i.e. an order with a broker). Our analysis is carried out at the ticket level. We therefore aggregate all trades belonging to the same order, by the same manager, executed through the same broker, on the same day.

Next, we provide the definition of a fire sale event. Our goal is to identify liquidity-motivated sales that attract brokers' attention and are likely to generate a significant price impact. Hence, we impose two requirements. For a given manager, the selling amount needs to exceed the manager's

\footnotetext{
${ }^{10}$ Relative to the standard release of Ancerno that is available to other researchers, we managed to obtain manager and broker identifiers also for the latest years (that is, after 2011), under the agreement that no attempt is made to identify the underlying institutional names.
} 
standard trading volume for a protracted period. At the stock level, the sale volume needs to make a sufficient fraction of total trading volume.

In more detail, to identify liquidating funds we start by computing the signed volume Z-score for each manager $m$ on day $t$ as

$$
\mathrm{Z}_{\mathrm{t}}^{\mathrm{m}}=\frac{D V o l_{t}^{m}-E\left(D V o l_{t}^{m}\right)}{\sigma\left(D V o l_{t}^{m}\right)}
$$

where $D V o l_{t}^{m}$ is the portfolio level dollar volume traded by manager $m$ on day $t$, and its mean and standard deviation are estimated over a rolling window of 120 trading days ending one week before day $t$. Then, for a given manager, we require that during a fire sale event if $\mathrm{Z}_{\mathrm{t}}^{\mathrm{m}}$ is below -0.25 for at least five trading days in a row. This requirement ensures that the sale is taking place on a sufficiently long period of time for the broker to realize about the fire sale and for it to represent a significant event in the life of the fund. In addition, we impose a filter at the stock level to ensure that the sale volume is large enough to generate price pressure. For stock $j$ to be part of the fire sale event, we require that the volume traded by the manager is at least $1 \%$ of the CRSP volume on day $t$ for at least four out of the five fire sale days.

We decide to keep events in which at least 10 stocks are involved in a fire sale. The goal is to reduce the probability that liquidating funds are selling as a consequence of stock-specific information. Focusing on liquidations of a large number of stocks makes it less likely that the sales are information driven.

We distinguish between aware and unaware brokers. Intuitively, we define a broker as aware of the fire sale if it intermediates a sufficiently large volume of a stock that is involved in a fire sale, as well as if the broker intermediates a sufficiently large volume of the fire sale basket of stocks. The second condition is imposed to ensure that the broker realizes that the liquidating fund is engaging in a large-scale portfolio liquidation, as opposed to trading a single stock for fundamental reasons.

In detail, the variable aware is a dummy, defined at the event-broker-stock-day level, indicating that the broker is aware of the fire sale happening on a given stock-day. That is, for broker $B$, stock $j$ on day $t$, the aware dummy equals one if the aware-broker quantity 


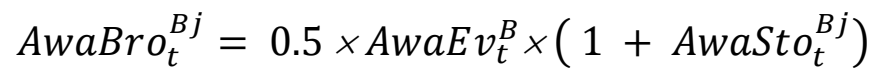

is above the $10 \%$ threshold. In equation (2), AwaSto $_{t}^{B j}$ is the stock-level awareness, defined as the ratio between the turnover intermediated by broker $B$ on stock $j$ up to day $t$ and the total turnover on stock $j$ up to day $t$ (across all active brokers). Stock-level awareness is meant to capture the fact that an aware broker observes an abnormal volume at the stock level. $A w a E v_{t}^{B}$ is the event-level awareness, i.e. the ratio between the turnover intermediated by broker $B$ on all the fire sale stocks up to day $t$ and the total turnover on all the fire sale stocks up to that day (across all the brokers that intermediate those stock on day $t$ ). Event-level awareness is meant to allow the broker to realize that a manager is engaging in a portfolio-level liquidation. The functional form in Equation (2) is imposed simply to require that the aware-broker variable $A w a B r o t^{B j}$ is between 0 and 1. Finally, the $10 \%$ threshold is chosen to have a sufficiently large level of awareness. This choice flags as 'aware' roughly $3.4 \%$ of the broker-stock pairs involved, which correspond to $6.6 \%$ of the liquidation volume on average across fire sales. Although the threshold is arbitrary, results are robust to variations between $1 \%$ and $30 \% .{ }^{11}$ To be clear, once a broker becomes aware on day $t$, it remains aware for the following days in the fire sale event, given that $A w a E v_{t}^{B}$ and $A w a S t t_{t}^{B j}$ are increasing over time by construction.

Panels A and B of Table 1 provide the summary statistics for the key variables in our analysis. We identify 385 fire sale events over the 1999-2014 period, each lasting at least 5 days and with the liquidating funds selling on average \$377 million worth of stock (median: \$177 million). Figure 1 displays the distribution of events over our sample period. It shows that the events are evenly distributed over time; in fact, even during the recessions highlighted in red, the number of events does not spike. This confirms that our methodology identifies funds subject to idiosyncratic shocks rather than market-wide events. Moreover, we can compute the fraction of the liquidated portfolio that the liquidation volume represents. In particular, we estimate the liquidating funds' portfolios by cumulating their trades over the two years prior to the fire sale. Then, we divide the total volume of sold stocks by the reconstructed portfolio size. We find this fraction to be sizeable at $9.16 \%$, on average. Arguably, this methodology tends to underestimate the liquidating managers' actual portfolio because we do not know their positions at the beginning of the estimation period, so that

\footnotetext{
${ }^{11}$ Appendix Table A1 provides the robustness tests for our main result (Table 2) with respect to different levels of this threshold.
} 
the fraction provides an upper bound. In any event, this evidence suggests that these large sales are unlikely to be inspired by stock-specific information.

On average, 22 stocks are heavily sold during a fire sale event, with about $\$ 17.2$ million sold in each stock, which indicates that these events involve more than just isolated stocks. Figure 2 shows the distribution of these events as a function of the number of stocks, from events involving 10 to 50 stocks, as well as the distribution of the volume of trades by the liquidating fund that can even reach more than two billion dollars in some cases. By cumulating trades over a two-year period, we impute a portfolio to each manager.

Fire sales are intermediated by an average of 29 brokers, while the number of aware broker per event is on average less than 2. Furthermore, the price of the stocks sold in the fire sale declines by $1 \%$ on average during the first five days of the event, but there is significant variation. In fact for the bottom quartile, the price drops by more than $5 \%$.

Finally, we provide evidence on the type of stocks the liquidating managers are selling. We construct a proxy for the portfolios of the liquidating managers by cumulating their trades over the prior 2 years. Then, for each stock in the fire sale, we compute the fraction of the total volume in the fire sale that it represents (in dollar terms). Panel $\mathrm{C}$ of Table 1 shows the results from regressions of the fraction of the fire sale that stock $j$ represents on its weight in the selling manager's portfolio, market capitalization, volatility, the Amihud (2002) ratio, and various measures of past performance at different horizons. We find that, after controlling for the quantity held by the manager (i.e. portfolio weight), the funds tend to sell the larger, more liquid, and less volatile stocks in their portfolio. Also, asset managers tend to sell the stocks with higher past performance. These findings resonate with the predictions of theoretical models discussing the optimal liquidation strategies in case of distress (Scholes 2000, Brown, Carlin, and Lobo 2010).

Corroborating our identification strategy for fire sales, the highly significant positive coefficient on the portfolio weight suggests that the liquidating funds are not building short positions; rather, they are selling positions that are already present in their portfolio. 


\section{Main Results}

This section starts by discussing our empirical strategy and then presents the main evidence on the role of brokers in spreading order flow information during fire sale events.

\subsection{Fire Sales}

We start our analysis by characterizing the fire sale events. Figure 3 plots the average (across stocks and events) daily signed volume (i.e. order imbalance) for the liquidating fund during the event window, where the zero is defined as the first day of the five-day window over which we identify the fire sale. The large negative volume before day 0 is due to the fact that, while liquidations likely start earlier, we impose stringent criteria for them to be defined a fire sale. We note that, although order imbalance starts recovering after about five days, it is still below zero after about fifteen days. This is important, because it highlights the nature of the sale: the liquidating fund does not repurchase the stocks back (even when we extend the horizon further out). Hence, this fact weakens the possibility that the liquidating fund is short selling the stock because it expects the price to decline, and then buys the stock back.

Figure 4, instead, plots the average DGTW adjusted cumulative returns for the stocks included in the fire sales across all the events. The returns are mostly flat pre-event and then start precipitating quite rapidly while the liquidating fund (for simplicity, the originator) is selling most intensely, i.e. during the five-day interval $[0,4]$, then to slowly recover over time. Specifically, we find that after about twenty days they are back to the pre-event levels. This is a faster reversal than what is found in the existing literature on fire sales (Coval and Stafford, 2007). On average, the price drops by almost $1 \%$ during the five-day event-time interval [0, 4], which we label liquidation period. Importantly, the fact that we observe a reversal over such a short horizon tends to rule out the possibility that the liquidation and the price decline are due to negative fundamental news on the stock. On the contrary, the price path is strongly consistent with price pressure following liquidity motivated trades.

Next, we turn to the tests trying to detect information leakage by brokers. First, if brokers are exploiting their privileged position, we should expect the trades that go through aware brokers to be more subject to predation than those that go through unaware brokers. We can formally test this hypothesis by estimating the following specification 


$$
\text { Predation }_{m, i, b, t}=\beta_{1} \text { Aware }_{b, t}+\varepsilon_{m, i, b, t}
$$

where Aware is a dummy equal to one if the broker executing the trades is aware on day $t$. The dependent variable, Predation $_{m, i, b, t}$, is a dummy equal to one if the client $m$ of broker $b$ trades in the same direction as the originator, i.e. demanding liquidity, on a stock $i$ on day $t$. The dummy equals zero if the client provides liquidity by trading in the opposite direction of the originator or the client does not trade on that stock-day. We also estimate specifications in which the dependent variable is defined as the predation dummy multiplied by the ratio of dollar volume of the broker's

clients to the market capitalization of the stock (this variable is standardized by subtracting the mean and dividing by standard deviation). The sample includes trades executed by all managers with all brokers in the database on the fire sale stocks. These specifications rely on heterogeneity across brokers for identification: some brokers are more exposed to order flow information as they intermediate a higher fraction of the liquidation by the liquidating fund. Standard errors are clustered at the broker level.

We present the results in Table 2. Columns (1)-(4) focus on the predation dummy, while columns (5)-(8) present the results for the volume-weighted dependent variable. Each column modifies the baseline specification (1) by adding different fixed effects. In the most conservative specification, we include day, manager, broker, and fire-sale event fixed effects, which ensure that our estimates are not driven by unobservable broker or manager characteristics.

We find that trades executed by aware brokers have $6 \%$ higher probability of predation, or equivalently, the volume of predatory trades is about $14 \%$ of a standard deviation larger for the clients of aware brokers. This is the first step towards a better understanding of the role of brokers in fostering predatory trading. The results show that the brokers who are more likely to realize that the fund is engaged in a large liquidation are also more likely to intermediate trades that are consistent with predatory trading.

\subsection{Best Clients and Predatory Trading}

To sharpen our identification, we focus on the aware brokers and test yet another implication of our information leakage hypothesis. If the aware brokers provide information about order flows from liquidating managers, and if the information rents can be dissipated by leaking to too many 
traders, we should expect this disclosure to be selective and to allow the broker to extract the highest rents. Thus, we should expect the brokers to favor their best clients. To proxy for the strength of the manager-broker relationship, we use information about both the volume and the commissions generated by manager $m$ with broker $b$ in a window of 6 months ending one month before the fire sale event. We use this data to form five different proxies for "best clients", which we employ throughout our analysis.

First, we look at clients that generate at least $5 \%$ of the total volume intermediated by the broker, which results into about $6 \%$ of managers tagged as best clients, on average. Second, we divide the volume originating from a given manager by the total volume intermediated by the broker, thus obtaining the percentage volume. Then, for each broker, we sort the managers in increasing order of volume and assign to each manager a score equal to the cumulative percentage volume generated by that manager and all the managers below. The third measure is computed in a similar fashion, but the dollar volume is replaced by the dollar trading commissions generated by the manager. Finally, we also consider two dummies that equal one if the last two variables are in the top decile. We compute these variables over the six months preceding the month in which the trading takes place.

To show that these variables identify a meaningful source of variation across managers, Table 3 regresses each measure on its previous quarter lag, controlling for broker and manager fixed effects. Consistently across proxies, we find that the manager-broker relationships are very persistent. This fact suggests that brokers might have an incentive to nurture these relationships over time and that the heterogeneity across clients of the same broker might be a relevant source of variation for identifying the effect of interest.

Having established the importance of these manager-brokers relationships, we can now introduce our baseline specification:

$$
\begin{aligned}
& \text { Predation }_{m, j, b, t}=\beta_{1} \text { Best Client }_{m, b, t} \times \text { Liquidation Period }_{t}+
\end{aligned}
$$

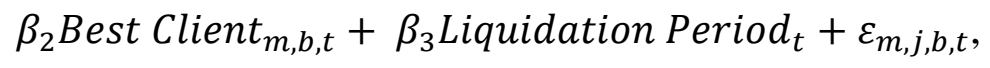

where, as before, our main dependent variable is the dummy indicating that manager $m$ sell its holdings of stock $j$ with the broker employed by the liquidating fund. This dependent variable has the advantage of being scale independent, i.e. the size of manager $m$ does not matter for our results. 
Best Client is a dummy in the first three columns and a continuous measure in Columns (4) and (5), depending on the measure employed to proxy for the strength of the relationship. Liquidation period is a time dummy equals to one for the first five days of the fire sale, that is, for the period of most intense liquidation by the fund in distress. The reference period is the time before the beginning of the fire sale. All specifications include time, manager, event, stock and broker fixed effects. We conservatively double-cluster the standard errors at both the stock and manager level, which allows for arbitrary correlation within trades in the same stock and by the same manager.

Table 4 presents the results. We find that the asset managers that are in a tighter relationship with the fire-sale-aware broker are significantly more likely to sell their holdings of the fire-sale stock with the same broker during the liquidation period. The results are both statistically and economically significant with the best clients being about $2 \%$ to $3 \%$ more likely to prey on the liquidating fund, which is equivalent to about half of the baseline predation probability, whose average is about $5 \%$. The results are also very consistent across proxies, which reassures us of the robustness of the estimates. ${ }^{12}$

A more stringent identification strategy exploits variation across managers as well as across brokers. That is, we compare the difference between the behavior of the best clients of the brokers that are aware of the fire sale and the behavior of the best clients of the brokers that are unaware, relative to the non-best clients of both types of brokers. Formally, Panel B of Table 4 reports the results from the following specification

$$
\begin{aligned}
& \text { Predation }_{m, j, b, t}=\beta_{1} \text { Best }_{\text {Client }}^{m, t} \times \text { Aware }_{j, b} \times \text { LiquidationPeriod }_{t} \\
& +\beta_{2}{\text { Best } \text { Client }_{m, t} \times \text { Aware }_{j, b}} \\
& +\beta_{3} \text { Best }_{\text {Client }}, t,{\text { Liquidation } \text { Period }_{t}} \\
& +\beta_{4} \text { Aware }_{j, b} \times{\text { Liquidation } \text { Period }_{t}}
\end{aligned}
$$

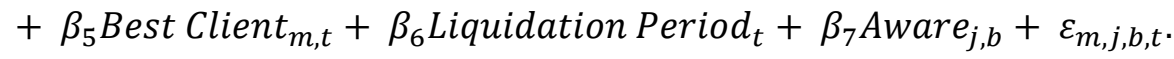

\footnotetext{
${ }^{12}$ To sharpen the identification, Table A2 in the appendix also reports the same specification with higher-dimensional fixed effects. Specifically, we include broker-manager and broker-originator fixed effects. This allows us to keep the pair broker-manager or broker-originator constant in our analysis: the variation comes from changes in the trading patterns between before and after the start of the liquidation, controlling for the typical trading pattern that characterizes a given pair. The results are unaffected.
} 
This specification confirms that the best clients of the aware broker are significantly more likely to sell the stock involved in the liquidation compared to the best clients of the other brokers involved in the liquidation. The results are consistent across measures of relationship, with the largest effects for the first measure based on size: the clients that submit at least $5 \%$ of an aware broker's volume are $11 \%$ more likely to prey on the liquidating fund. In the next set of robustness checks, for ease of exposition, we are going to present the results focusing on the set of aware brokers and exploit only variation across clients in terms of the strength of the broker-client relationship.

\subsection{Robustness to Aggregate and Stock-Specific News}

Having established that the best clients of the aware brokers are more likely to sell the same stock as the distress fund during the liquidation period, we examine whether the results can be driven by other factors than information leakage by the broker. The main alternative hypothesis that might explain these results is that asset managers are responding to the same common shock occurring during the same event windows. This might occur for two reasons. First, there might be a common disruption in the market that leads funds to offload their positions. Alternatively, news about the specific stocks might be released, triggering the funds' trading behavior.

We provide several direct tests to rule out these alternative explanations. The first step to ensure that the correlation among traders is not due to general disruption in the market is to exclude the two recessions in our sample, i.e. the tech crunch and the financial crisis. Panel A of Table 5 presents these results. It shows that the results are robust to this change in the estimation sample, with both the economic and statistical significance being unaffected.

Next, we test whether negative stock-specific news might explain our baseline results. To do so, we collect information about earnings announcements and changes in analyst recommendations. Intuitively, earning announcements might work as a catalyst, and a negative surprise might trigger a series of liquidations. We exclude ten trading days around the

announcements. Another important piece of fundamental information that might drive funds' behavior is changes in analyst recommendations. One might reasonably expect that multiple liquidations might follow a downgrade, especially an unexpected one. Therefore, we also exclude these events from our sample. Earnings announcements and analyst recommendations are not the 
only news that might trigger a coordinated response from market participants. In order to have the most comprehensive information about stock-specific news, we use the data provided by Ravenpack. The dataset is generated as the result of a comprehensive analysis of all types of information from newswires about each stock, from lawsuit to mergers and acquisitions. A machine learning algorithm is then employed to classify the news in good and bad on a scale from 0 to 100 , where 50 is the cutoff below which news are identified as bad. Even in the restricted sample excluding bad news, we confirm in Panel B of Table 5 that the best clients of aware brokers are more likely to predate on the liquidating manager.

Another instance in which fund managers might find themselves trading in the same direction is when the stocks belong to the same strategy, e.g. momentum, which might be commonly adopted by multiple funds. Furthermore, asset managers might be liquidating underperforming stocks. Then, as an additional robustness check, in Panel A of Table 6 we exclude from our sample all stocks exhibiting negative momentum. Specifically, we compute the returns of the stocks sold during the fire sale and exclude those with negative returns in the week preceding the fire sale. The results are unaffected.

To check whether our results could be driven by changes in investors' expectations about the stocks, Panel B of Table 6 also considers short selling data from Markit (formerly DataEx database). Intuitively, stocks with high short interest might be subject to correlated sales across funds, which might be triggered by company specific events or investors' common beliefs about the stock performance, rather than by the desire to take advantage of a liquidating fund. Then, we show the robustness of our results to the exclusion of events where the liquidated stocks exhibit a significant level of short interest, defined as a utilization ratio (i.e. shares on loan divided by shares available to lend) in the top quartile.

As an additional test to rule out the alternative hypothesis that funds are responding to similar shocks rather than deliberately taking advantage of the fire sale, we explore the number of stocks that are affected by the predatory behavior of the aware broker's clients. The idea is that if investors are simply responding to a common shock to a stock, we might find that their sales are concentrated on that particular stock. On the other hand, if multiple stocks out of the 20 that are involved on average in a fire sale are sold by the best clients of the aware broker, predation on the liquidating fund seems more likely. To test this conjecture, Table 7 reports results where the outcome variable 
is the number of fire-sale stocks for which the manager sells its holdings (Panel A), and the fraction of stocks involved in the fire sales for which we observe predatory behavior (Panel B). We find that best clients of the aware brokers tend to sell their holdings on 3 to 4 more stocks, and to predate about $15 \%$ more of the stocks involved in the fire sale. ${ }^{13}$

\subsection{Evidence of Trade Reversion}

To corroborate the hypothesis that our results are driven by predatory behavior by the asset managers who are able to acquire order flow information via the broker, we test whether these same asset managers are also likely to cover their positions by repurchasing the stock in the following days. As predicted by Brunnermeier and Pedersen (2005) and Di Maggio (2016), asset managers who prey on liquidations should sell the asset while its price is moving away from fundamentals and then revert their positions once the liquidating fund has stopped exerting selling pressure pushing the price upwards.

To this purpose, we compute the fraction of a manager's negative position that is subsequently reversed. In detail, the percentage of position reversed for manager $m$ during event $e$ for stock $j$ is defined as the ratio $\operatorname{Rev}_{e, m, j}=$ BoughtBack $_{e, m, j} / \operatorname{Sold}_{\mathrm{e}, \mathrm{m}, \mathrm{j}}$, where Sold $_{\mathrm{e}, \mathrm{m}, \mathrm{j}}$ is the dollar sum of all sell orders in that period, and BoughtBack $k_{e, m, j}$ is the dollar sum of buy orders during the period, where we sum only the buy orders that are preceded by a negative cumulative order flow. Our motivation is to avoid counting as reversals the buy orders that occur before sales have taken place. We compute this measure around each fire sale event, for the ten days before and after the fire sale. We then compare the percentage of position reversed by Best and Non-Best clients of the aware brokers before and after the fire sale events. The liquidating funds are excluded from the sample.

In Table 8, we find that a significant fraction of the predating managers' positions, ranging from $12 \%$ to $40 \%$, is covered in the ten days following the fire sale. We interpret this evidence as strong

\footnotetext{
${ }^{13}$ As further robustness test, in Table A3 in the appendix, we report the baseline regressions of Table 4 using as main dependent variable the predation dummy multiplied by the trading volume as a fraction of the stock market capitalization. Panel A shows the results for the whole sample, while, for brevity, Panel B shows the results for the most restrictive subsample, i.e. the one excluding at the same time recession, negative news, as well as high short interest and negative momentum stocks. The results are statistically significant, with best clients generating larger selling pressure in dollar terms during the liquidation period. This wedge is also economically significant, as it corresponds to an average increase of up to $13 \%$ of a standard deviation of their order flow in the direction of the originator.
} 
indication that the predating managers were motivated by the prospect of short-term gains at the expense of the liquidating fund.

\subsection{Late-Trading Scandal as a Natural Experiment}

We can envisage two alternative interpretations to the proposed view that order flow leakage by brokers explains our evidence. First, selling pressure on a stock might be generated by changes in market sentiment about that stock rather than by a shock to the fund holding that stock. Second, the intermediating broker can be the original source of the information about the liquidated stocks, which then triggers the large sale as well as smaller sales by other managers in the same direction.

The evidence so far seems to weaken the validity of these alternative explanations. First, our identification of fire sales suggests that these liquidations involve a large fraction of a manager's portfolio (9.16\% on average) and involve at least 10 different stocks (on average 22 stocks). Hence, it is unlikely that the liquidating managers are responding to stock-specific information or to a broker trading tip. Second, the robustness tests in Tables 5 and 6 show that the evidence remains unchanged when removing stock-specific and aggregate informational events from the sample.

To further rule out these alternative explanations, we identify an exogenous determinant of fire sales. In particular, we need a driver of liquidations that is manager-specific, i.e. it is not inspired by the broker, and which does not depend on the identity of the liquidated stocks or the composition of the manager's portfolio.

Anton and Polk (2014) use the liquidations triggered by outflows following the late-trading scandal as a natural experiment to identify exogenous selling activity (also see, Kisin 2011). We follow these authors and focus on the mutual fund scandal that erupted in September 2003. At the time, the New York Attorney General Eliot Spitzer announced the discovery of illegal late trading activities and market timing practices on the part of several hedge fund and mutual fund companies. The scandal had a significant impact on the 27 fund families involved: they experienced significant outflows as they lost $14.1 \%$ of their capital within one year and $24.3 \%$ within two years (Kisin, 2011). This is an ideal experiment for our purposes because it allows us to identify stocks that for exogenous reasons are subject to selling pressure. Although market participants were aware that these fund families were experiencing investors' outflows, the 
brokers' vantage point allows them to pin down when these funds were liquidating and which stocks were involved in the liquidation. Both pieces of information are fundamental in making the predation profitable and they are not publicly available.

To test whether even in this case, the brokers are responsible for leaking information about the stocks that are liquidated and the timing of these liquidations, we manually match the identity of the fund families included in Spitzer's complaint with our trade-level dataset, in order to identify the sales trades of these fund families and the brokers through which they execute them. ${ }^{14}$ Corroborating the validity of our matching procedure, we find that the matched managers rank in the top quartile by sales in the two-year period following the breakout of the scandal.

Then, we focus on daily transactions of the managers that are not involved in the scandal for a period of four years centered on the month of the announcement of the complaint by Spitzer

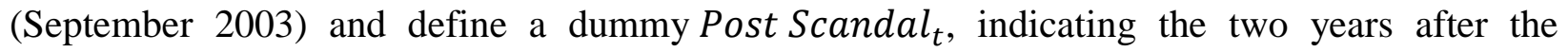
complaint broke out. Next, we define a broker-stock-day level dummy variable, Selling $g_{b, j, t}$, indicating that at least one of the charged funds is selling stock $j$ on day $t$ through broker $b$. Then, we define the dependent variable Probability of Predation as a dummy variable that equals 1 if a non-charged manager is selling stock $j$ on day $t$ through broker $b$. The dependent variable equals 0 if a non-charged manager trades on a different day, or on a different stock, or with a different broker. In a difference-in-differences setting, we regress the probability of predation on the interaction between Selling ${ }_{b, j, t}$ and the dummy Post Scandal . $_{\text {. }}$

Table 9 reports the estimates. Consistently with the previous baseline results, we find that the clients of the brokers employed by the funds involved in the scandal were significantly more likely to liquidate the same stocks after the scandal broke out. For example, in Column (1), there is a 4.3\% higher probability of non-charged managers to trade in the same direction as a charged manager on the same day through the same broker.

These results corroborate the interpretation that the clients of the aware brokers adopt predatory trading strategies to take advantage of temporary price movements due to fire sales, and that these results cannot be explained away by shocks to the market or to the single stocks as well as by a

\footnotetext{
${ }^{14}$ A complete list of the fund families involved in the scandal arising from Spitzer's complaint can be found on the webpage: https://en.wikipedia.org/wiki/2003_mutual_fund_scandal\#List_of_implicated_fund_companies.5B4.5D.5B5.5D. Out of the 27 families that are involved, we are able to find a match in our dataset for 19 of them.
} 
common response to the release of public information, given that the timing of the sales and the identity of the stocks that are sold is information to which only the intermediating brokers have access. Moreover, the interpretation relying on the idea that brokers are generating stock-specific trading ideas seems implausible, given that there is no reason for this activity to increase after the breakout of the scandal.

\subsection{Heterogeneity}

We exploit the granularity of our data to further explore whether the predatory trading behavior depends on the characteristics of the clients.

We should expect the most active managers in the sample to be the ones more willing and capable of taking advantage of the liquidating funds' trades. To proxy for these characteristics, we can investigate whether the results differ for hedge funds and other institutions. Intuitively, hedge funds are more likely to have the ability to promptly react to information released by the brokers than mutual funds or pension funds. We manually identify the hedge funds in Ancerno following the procedure in Franzoni and Plazzi (2015).

Panel A of Table 10 reports the baseline specification in Equation (1) for hedge funds, while Panel B focuses on other institutions. The results clearly show that the hedge funds are the main driver of our results. In fact, the magnitude of the coefficients is higher than in the baseline regressions of Table 4, while the statistical significance, as well as the economic significance, is weaker for the non-hedge funds. This evidence corroborates the hypothesis that the behavior we observe is a deliberate attempt by the smart money to take advantage of temporary price fluctuations.

\section{The Value of Order Flow Information}

\subsection{Profitability of Predatory Strategies}

An important question at this point is whether the asset managers that receive the information from the broker are able to generate higher abnormal returns. Hence, we study whether predatory trading is indeed profitable. 
To address this question, we compute the profits that asset managers generate during the fire sales. In particular, starting from the first day of the liquidation (day 0), at the close of each day we compute the marked-to-market value of the net position in a given stock and subtract from this value the net cash amount that was necessary to build that position over the period. To express these profits as a fraction of capital at risk, we divide them by the absolute value maximum dollar outlay over the period in which the profits are computed. ${ }^{15}$

We start by showing in Figure 5 the profits of managers that are best clients of aware and unaware brokers at the daily frequency after the start of the fire sale. Intuitively, if as shown in Table 2 the trades executed by unaware brokers are significantly less likely to be predatory, we should find that their clients are also less likely to profit from these fire sales events. Indeed, the figure shows that the clients of aware brokers are able to capture significant returns after the start of the liquidation, while the trades of the clients of unaware brokers do not generate significant profits. The profits for the best managers peak at about 50 bps 17 days after the start of the fire sale.

Next, to provide more systematic evidence from regression analysis, we estimate the following specification:

$$
\begin{aligned}
\text { Profits }_{m, i, b, t} & =\beta_{1}{\text { Best } \text { Client }_{m} \times \text { Liquidation Period }_{t}+\beta_{2} \text { Best }_{\text {Client }}} \\
& +\beta_{3} \text { Liquidation Period }_{t}+\varepsilon_{m, i, b, t}
\end{aligned}
$$

which tests whether a manager $m$ 's profits are significantly higher in the ten days after the start of the fire sale relative to the prior ten days, whenever the manager is one of the best clients of the aware broker. Intuitively, as with the estimation of the predation probability, we are comparing the behavior of managers that should be aware of the fire sale, given their relationship with the broker, with those who are likely not, before and after the beginning of the fire sale. We allow for a tenday window to allow managers the time to close their predatory short positions that they likely

\footnotetext{
15 To be clear, we subtract stocks that are sold from stocks that are bought to compute the net position, which can end up being negative, as in a short sale. The net cash amount to build the position can also be negative if the buy transactions exceed in dollar value the buy transaction. This fact implies that when we compute the maximum exposure, we need to use the absolute value.
} 
accumulate during the first five days of the fire sale, which is the period over which on average the stock price declines (see Figure 4). ${ }^{16}$

Table 11 reports the results showing that aware brokers' best clients exhibit significantly higher profits than other managers. On average, the best clients are able to generate between 47 and 74 basis points in five days, depending on the relationship proxy. Considering the low average performance of institutional asset managers (see, among others, Busse, Goyal, and Wahal, 2010) these higher returns are, indeed, highly economically significant.

One might wonder whether the clients of aware brokers are always able to generate higher profits than the clients of unaware brokers. If this were the case, then what we have shown in the previous table could be explained by the different characteristics of the managers rather than by the privileged access to order flow information. Although we already control for manager-fixed effects, we also directly test for this possibility in Figure 6, which provides a placebo test. The figure reports the profits for the two groups of managers, but for a random sample of event windows other than the ones included in our fire-sale analysis. We show that the two groups are indistinguishable in terms of their performance during these other times, which corroborates the interpretation that the superior performance we document in Table 11 is made possible by the access to the fire sale information.

\subsection{Price Impact}

Having established that the predatory traders are able to capture significant returns, we investigate the dark side of predation. The conjecture is that predatory volume causes stock prices to decline significantly more than what they would do in the absence of predation. In turn, this steeper decline in prices leads the liquidating fund to achieve lower returns on its sale trades.

Testing this conjecture requires the specification of a counterfactual. Fortunately, we can identify fire sales events for which there are no aware brokers. These are 29 events (i.e. $7.5 \%$ ) out of a total of 385 events. In these situations, no broker observes a large enough fraction of the liquidation to be deemed aware according to the criteria specified in Section 2. According to our

\footnotetext{
${ }^{16}$ Of course, the positions could be closed before day 5 and still be profitable. Our methodology for computing profits is flexible enough to allow for all such possibilities.
} 
identification strategy, no information leakage occurs on these events. More realistically, the information leakage is expected to be significantly lower.

Based on this strategy, we run event-stock level regressions of price impact onto the broker awareness dummy. The broker awareness dummy denotes situations in which there is at least one aware broker for that stock-event. The price impact is computed as execution shortfall, i.e. the percentage difference between the execution price and a benchmark price (e.g. Keim and Madhavan, 1997).

We use three different benchmarks to show that our results do not crucially depend on a single measure. Specifically, we use the price at the placement time of the first fire sale trade, the open price of the day of the first fire sale trade, and finally the transaction price of the first fire sale trade. In all specifications, we control for the volume in the fire sale, the volume of the following trades (i.e. the trades in the same direction over the same five-day window), and the liquidity of the stock (Amihud, 2002, Illiquidity Ratio), as they are all potentially important drivers of price impact. In more detail, for each benchmark price we compute the implementation shortfall at the ticket-level for the sales by the liquidating funds during the liquidation period as

$$
\frac{\text { TransactionPrice - BenchmarkPrice }}{\text { BenchmarkPrice }} .
$$

We then average this quantity at the event-broker level, using as weights the volume of each transaction, to obtain an event-broker level measure of price impact.

Results are reported in Table 12. In Panel A, we regress these price impact measures on the aware broker dummy. Consistently across measures, we show that the price impact costs borne by the liquidating funds are significantly higher when they trade with brokers who are aware of the liquidation event. The estimates are also economically significant as the price impact increases by at least 22 bps and up to 40 bps. These numbers amount to between $11 \%$ and $26 \%$ in standard deviation units. In Panel B, we exploit the granularity of our data and run a similar specification in an event-stock-broker level sample. In this case, for the same stock-event, we can have aware and unaware brokers. We can then include broker fixed effects to control for the possibility that heterogeneity in price impact results from difference in broker execution quality. The results remain significant and the magnitude decreases only slightly. 
Finally, we can provide a graphical description of the difference in price paths between the case in which brokers have the possibility to leak (aware brokers) and the case in which brokers do not have information about the liquidation (unware brokers). Figure 7 plots the cumulative return of the fire sale stocks during fire sale events. The red line with squares represents the cumulative return averaged across these stocks and events for the aware brokers. The green line with circles is an estimation of the counterfactual cumulative return, based on unaware brokers. The series draw on estimates from a regression specification similar to the one reported in Table 12, Panel B, but run on daily observations starting on day 0. More precisely, the vertical distance between the two series is the estimate of the aware broker dummy for a specific day of the interval.

Figure 7 is a useful way to show that the transaction cost of the liquidating funds almost doubles in the presence of predatory trading. At the trough of price impact, day 3 , the cumulative return is about -70 bps with aware brokers and about -35 bps in case of unaware brokers, i.e. the case in which we conjecture that no leakage occurs.

\section{Further Evidence}

In this section we provide further evidence that is consistent with the interpretation founded on order flow leakage and predatory trades.

\subsection{Persistence in the Number of Brokers}

One could wonder why the liquidating funds do not better hide their trades to avoid this higher price impact. There are several non-mutually exclusive explanations. First, the evidence suggests that in fact they try to hide their trades as they tend to employ an average of about 29 brokers to intermediate these trades. Second, the funds are most likely in a rush to liquidate, which makes them prioritize execution speed over price impact. For the same reason, they are likely to rely on familiar brokers, as opposed to search for other brokers, which can take time. Third, there is a significant amount of stickiness in the trading relationships between brokers and their clients. We reported in Table 3 the persistence of these relationships. Here, we provide information on the persistence in the number of brokers that managers use. Table 13 reports the autocorrelation of various measures of concentration, such as the number of brokers and the Herfindahl index, both 
on average and during fire sales events. The striking result is that indeed asset managers tend to concentrate their trades among few brokers, and they do it both when they are seeking liquidity and when they are not. It appears, therefore, that managers find it difficult to start interacting with new brokers, i.e. building new relationships with brokers, at the time when a timely execution of their trades is needed to meet investors' redemptions demands.

\subsection{Quid Pro Quo}

Another natural question is whether brokers gain from leaking order flow information about their clients. One might argue that it would be in their best interest to build a reputation as a loyal trading partner by keeping the order flow information private. On the other hand, brokers have an incentive to increase the volume they intermediate as they are paid on commissions. We can address this question by exploiting the granularity of our data and testing whether best clients tend to reward the brokers by channeling more trades to them. Table 14 regresses the average Commission per dollar $r_{e, m, b, t}$ paid by manager $m$ to broker $b$ during month $t$, defined as the ratio of the total amount in dollars paid in commissions and the total dollar volume traded by manager $m$ and intermediated by broker $b$ in that month, on the interaction of the dummy variable identifying the two years following the fire sale event with each of our Best Clients proxies. ${ }^{17} \mathrm{We}$ find that the clients who are more likely to receive order flow information tend to increase their commissions to the brokers, which strongly suggests a quid pro quo between these parties.

\subsection{Hedging Trades}

Finally, the predatory trading strategy which seems to emerge from the main findings of this paper is not devoid of risk, as prices may fail to drop. Also, this is not a risk that can be diversified within a portfolio of similar trades, given that there are hardly multiple liquidations occurring at the same time and, even if there were multiple liquidations, a manager is unlikely to have contacts with multiple leaking brokers. Then, a smart way to implement this strategy would be for the predators to hedge their short positions on the fire sale stocks with long positions on other similar stocks.

\footnotetext{
${ }^{17}$ We have performed a similar analysis in which, instead of the proxies for best clients, we look at the clients that are more likely to predate on that stock in that event, which we identify as those that are in the top half of the distribution of profitability in the tenday window after the event. Also, we run the same analysis focusing on brokers' clients that trade in the same direction as the liquidating fund during the liquidation periods. In both cases, the results (reported in Appendix Table A4, Panels A and B) are very similar to those in Table 14.
} 
This would also allow the asset managers to reduce exposure to aggregate risk. To search for evidence of hedging trades, we first define substitute stocks as those belonging to the same industry or industry group as the fire sale stock, as identified with the 4-digit Standard Industry Classification Code (SIC4) or by the SIC3, respectively.

For each fire sale event, we consider ticket-level transactions of the best clients of aware brokers (as defined by our awareness measure and the five Best Client proxies) on all the stocks other than those that are involved in the fire sale, in a window of 5 trading days on each side of the start of the liquidation event. Fire sale originators are excluded from the sample. The dependent variable is a dummy variable Hedging $_{e, i, m}$ defined at the event-manager-stock level indicating buy trades of manager $m$ on stock $i$ such that manager $m$ sold stock $j$ during event $e$ and the stocks $i$ and $j$ are substitutes. The variable takes the value of zero for buy trades that are not in substitute stocks and for sell trades. We regress the dependent variable on the interaction of the aware dummy and the liquidation period dummy. In this case, the aware dummy is constructed at the manager-stock level and indicates whether the manager is a best client of an aware broker intermediating a fire sale in the same industry as that of the stock under consideration.

In Table 15, consistent with a hedging strategy by the asset manager predating on the fire sales, we find that predating managers are significantly more likely to buy substitute stocks in the fiveday window after the beginning of the fire sale. This evidence further corroborates the interpretation of a deliberate predatory behavior by the best clients of aware brokers.

\section{Conclusion}

This paper studies whether brokers' incentives to attract and retain clients crucially induce sharing of flow information with other market participants. The evidence suggests that brokers tend to reveal the occurrence of a fire sale to their best clients, allowing them to generate significant profits by predating on the liquidating fund. Furthermore, this information leakage comes at the expense of higher price impact, and leads to a more costly liquidation for the fire sale originator.

These findings have implications for academics, practitioners, and policy makers. First, our results indicate an important cost associated with slow execution. Slow execution has been widely advocated by academics as a way to minimize price impact since Kyle (1985) and routinely 
implemented by practitioners. In fact, according to our results, executing large trades over multiple days allows the brokers to forecast order flow and to trigger predatory behavior by other market participants. This might adversely affect price impact.

Information leakage might be a source of concern for regulators as well, since it might exacerbate the costs associated with fire sales, especially at times of scarce liquidity. Regulations are unclear on what type of information the brokers can and cannot share with their clients. Specifically, brokers have an obligation of "best execution", which has two dimensions: price and speed. Leaking information about a stock involved in a fire sale can worsen the price at which the liquidating fund is able to execute its trades, as it appears from our evidence. On the other hand, leaking brokers can always appeal to the defense argument that they spread the information in an attempt to rapidly find trading counterparties for the liquidating fund. This defense argument is weak, however, given the evidence of a quid pro quo that we present in the paper. That is, the predatory managers seem to reward the leaking brokers with more revenues in the future. Yet, a regulatory attempt to stop information leakage is likely to be challenging, because it will have to deal with the brokers' need to operate as deal-makers, as well as with the reluctance of many asset managers to disclose more information about their trading activities.

A fruitful avenue for further research is to build upon the insights of this paper towards a more articulated theory of how the relationship between asset managers and intermediaries, such as brokers, affects trading behavior and asset prices. Specifically, one could structurally estimate how the flow of information diffuses among market participants and address questions about the efficiency of such strategic behavior by the brokers for price discovery and asset allocation, as well as providing insights into the counterfactual results in the presence of new regulations aimed at curbing this practice. 


\section{References}

Acharya, Viral V., Douglas Gale, and Tanju Yorulmazer, 2011, Rollover risk and market freezes, Journal of Finance 66(4): 1177-1209.

Afonso, G., Kovner, A. and Schoar, A., 2013. Trading partners in the interbank lending market. FRB of New York Staff Report, (620).

Allen, Franklin, and Douglas Gale, 1994, Limited Market Participation and Volatility of Asset Prices, American Economic Review, 84(4): 933-55.

Amihud, Yakov, 2002, Illiquidity and stock returns: cross-section and time-series effects, Journal of Financial Markets, 5(1): 31-56.

Anand, Amber, Paul Irvine, Andy Puckett, and Kumar Venkataraman, 2012. Performance of institutional trading desks: An analysis of persistence in trading costs. Review of Financial Studies, 25, 557-598.

Anand, Amber, Paul Irvine, Andy Puckett, and Kumar Venkataraman, 2013. Institutional trading and stock resiliency: Evidence from 2007-2009 financial crisis. Journal of Financial Economics, 108, 773-793.

Anton, Miguel, and Christopher Polk, 2014, Connected Stocks, Journal of Finance 69(3), 10991128.

Babus, A. and Kondor, P., 2016. Trading and information diffusion in over-the-counter markets. Working Paper, London School of Economics.

Brown, David B., Bruce Ian Carlin, and Miguel Sousa Lobo, 2010, Optimal Portfolio Liquidation with Distress Risk, Management Science 56, 1997-2014.

Brunnermeier, Markus K., and Lasse Heje Pedersen, 2005, Predatory trading, Journal of Finance 60(4), 1825-1863.

Brunnermeier, Markus, and Lasse H. Pedersen, 2009, Market Liquidity and Funding Liquidity, Review of Financial Studies, 22(6): 2201-38.

Busse, Jeffrey A., Amit Goyal, and Sunil Wahal, 2010, Performance and persistence in institutional investment management. Journal of finance 65(2): 765-790. 
Coval, J. and Stafford, E., 2007. Asset fire sales (and purchases) in equity markets. Journal of Financial Economics, 86(2), pp.479-512.

Chung, J.W. and Kang, B.U., 2016. Prime Broker-Level Comovement in Hedge Fund Returns: Information or Contagion? Available at SSRN 2396522.

Diamond, Douglas W., and Raghuram G. Rajan, 2011, Fear of Fire Sales and the Credit Freeze, NBER Working Paper 14925.

Di Maggio, Marco, 2016, Market Turmoil and Destabilizing Speculation. Columbia Business School Research Paper No. 13-80. Available at SSRN: https://ssrn.com/abstract=2353133 or http://dx.doi.org/10.2139/ssrn.2353133.

Di Maggio M., Kermani A., Song Z., 2017. The Value of Trading Relations in Turbulent Times. Journal of Financial Economics, Volume 124, Issue 2, Pages 266-284.

Di Maggio, Marco, Francesco Franzoni, Amir Kermani, and Carlo Sommavilla. The relevance of broker networks for information diffusion in the stock market. No. w23522. National Bureau of Economic Research, 2017.

Di Mascio, Rick and Lines, Anton and Naik, Narayan Y., 2016. Alpha Decay and Strategic Trading. Working Paper

Duffie, Darrell, Semyon Malamud, and Gustavo Manso, 2009. Information Percolation With Equilibrium Search Dynamics. Econometrica, 77(5): 1513-1574.

Duffie, Darrell, Semyon Malamud, and Gustavo Manso, 2014. Information percolation in segmented markets. Journal of Economic Theory, 153, pp.1-32.

Farboodi, Maryam, and Laura Veldkamp, 2017, Long Run Growth of Financial Technology. Working Paper.

Franzoni, Francesco, and Alberto Plazzi, 2015, Do Hedge Funds Provide Liquidity? Evidence from their Trades. Swiss Finance Institute Working Paper.

Garleanu, Nicolae, and Lasse Heje Pedersen, 2011, Margin-based asset pricing and deviations from the law of one price, Review of Financial Studies 24(6): 1980-2022.

Gârleanu, Nicolae, and Lasse Heje Pedersen, 2013, Dynamic trading with predictable returns and transaction costs. The Journal of Finance 68(6): 2309-2340. 
Geanakoplos, John, 2003, Liquidity, Default, and Crashes: Endogenous Contracts in General Equilibrium. In Advances in Economics and Econometrics: Theory and Applications, Eighth World Congress, Vol. II, ed. Mathias Dewatripont, Lars Peter Hansen, and Stephen J Turnovksy, 170-205. Cambridge University Press.

Gromb, Denis, and Dimitri Vayanos, 2002, Equilibrium and Welfare in Markets with Financially Constrained Arbitrageurs, Journal of Financial Economics, 66(2-3): 361-407.

Goldstein, Michael A., Paul Irvine, Eugene Kandel, and Zvi Wiener, 2009, Brokerage commissions and institutional trading patterns, Review of Financial Studies 22(12), 5175-212.

Hendershott, T., Li, D., Livdan, D. and Schürhoff, N., 2016. Relationship trading in OTC markets. Swiss Finance Institute, Working Paper.

Hollifield, Burton, Neklyudov, Artem and Spatt, Chester S., 2016, Bid-Ask Spreads, Trading Networks and the Pricing of Securitizations, Review of Financial Studies, forthcoming.

IAFE Investor Risk Committee (IRC), 2001, Hedge fund disclosure for institutional investors. Available at http://www.iafe.org/committees/investor/riskconsensus.htm.

Keim, Donald B., and Ananth Madhavan, 1997, Transactions costs and investment style: an interexchange analysis of institutional equity trades, Journal of Financial Economics 46(3): 265-292.

Kisin, R. 2011. The impact of mutual fund ownership on corporate investment: Evidence from a natural experiment. Working Paper, Washington University in St. Louis.

Kyle, Albert S., 1985, Continuous auctions and insider trading, Econometrica, 1315-1335.

Lorenzoni, Guido, 2008, Inefficient Credit Booms, Review of Economic Studies, 75(3): 809-33.

Puckett, Andy, and Xuemin (Sterling) Yan, 2011. The interim trading skills of institutional investors. Journal of Finance, 66, 601-633.

Scholes, Myron 2000, Crisis and Risk Management, American Economic Review 90,17-21.

Shleifer, Andrei, and Robert Vishny, 2011, Fire sales in finance and macroeconomics, Journal of Economic Perspectives 25(1), 29-48.

Stein, Jeremy C., 2012, Monetary Policy as Financial Stability Regulation, Quarterly Journal of Economics, 127 (1): 57-95 
Van Kervel, Vincent and Menkveld, Albert J., 2016. High-Frequency Trading around Large Institutional Orders. Working Paper.

Walden, Johan, 2016. Trading, profits, and volatility in a dynamic information network model. Available at SSRN 2561055.

Yang, Liyan, and Haoxiang Zhu, 2016, Back-running: Seeking and hiding fundamental information in order flows, Rotman School of Management Working Paper 2583915. 


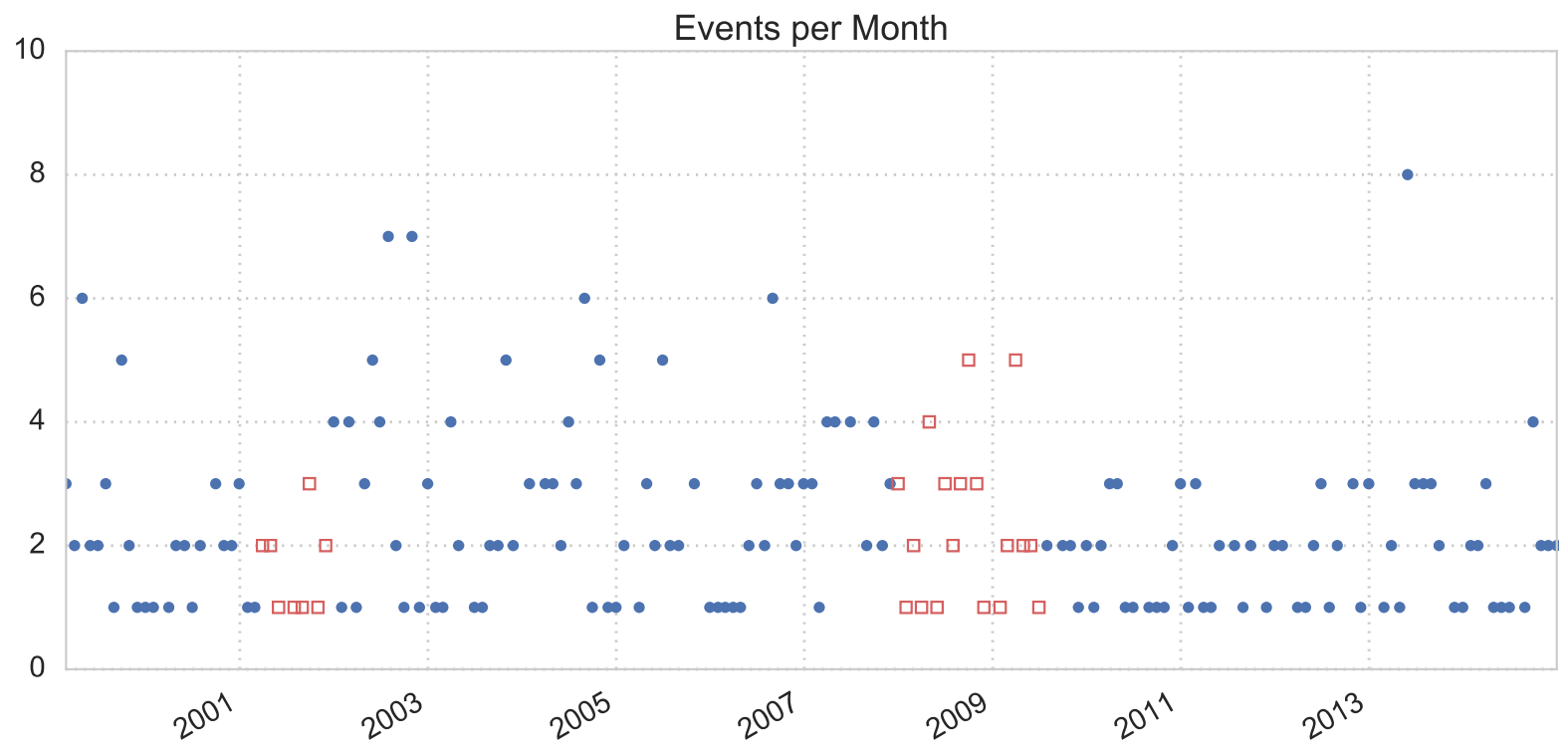

Figure 1: Fire Sale Events. The figure plots the number of fire sales events by month. Hollow red squares identify events happening during the two NBER recessions in our sample period.
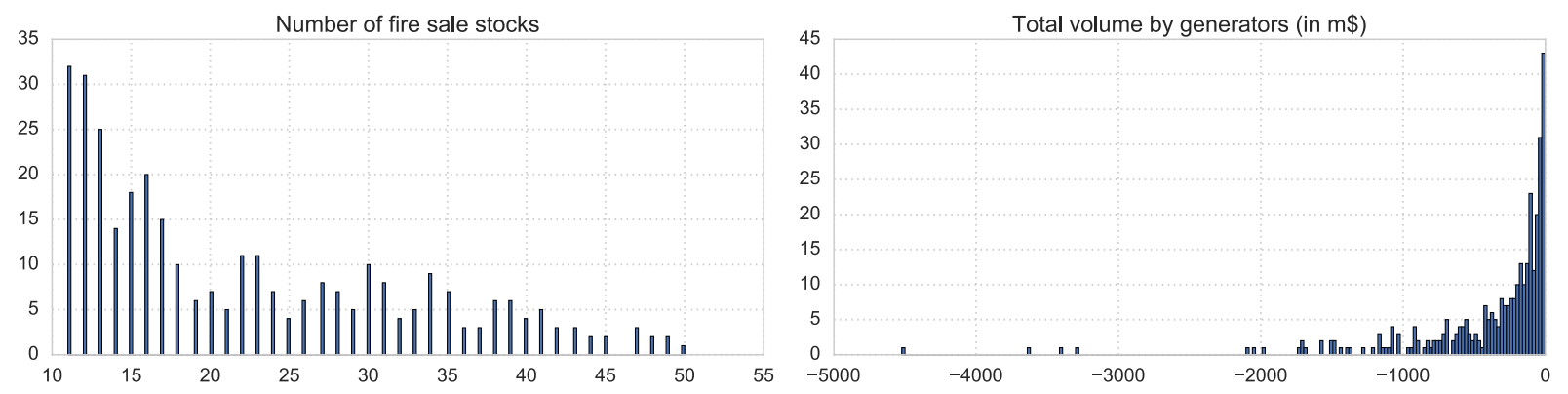

Figure 2: Number of Stocks and Liquidation Volume. The left panel shows the histogram of events with different number of stocks involved in the fire sale. The right panel shows the distribution of the total volume executed by the liquidating funds (generators). 


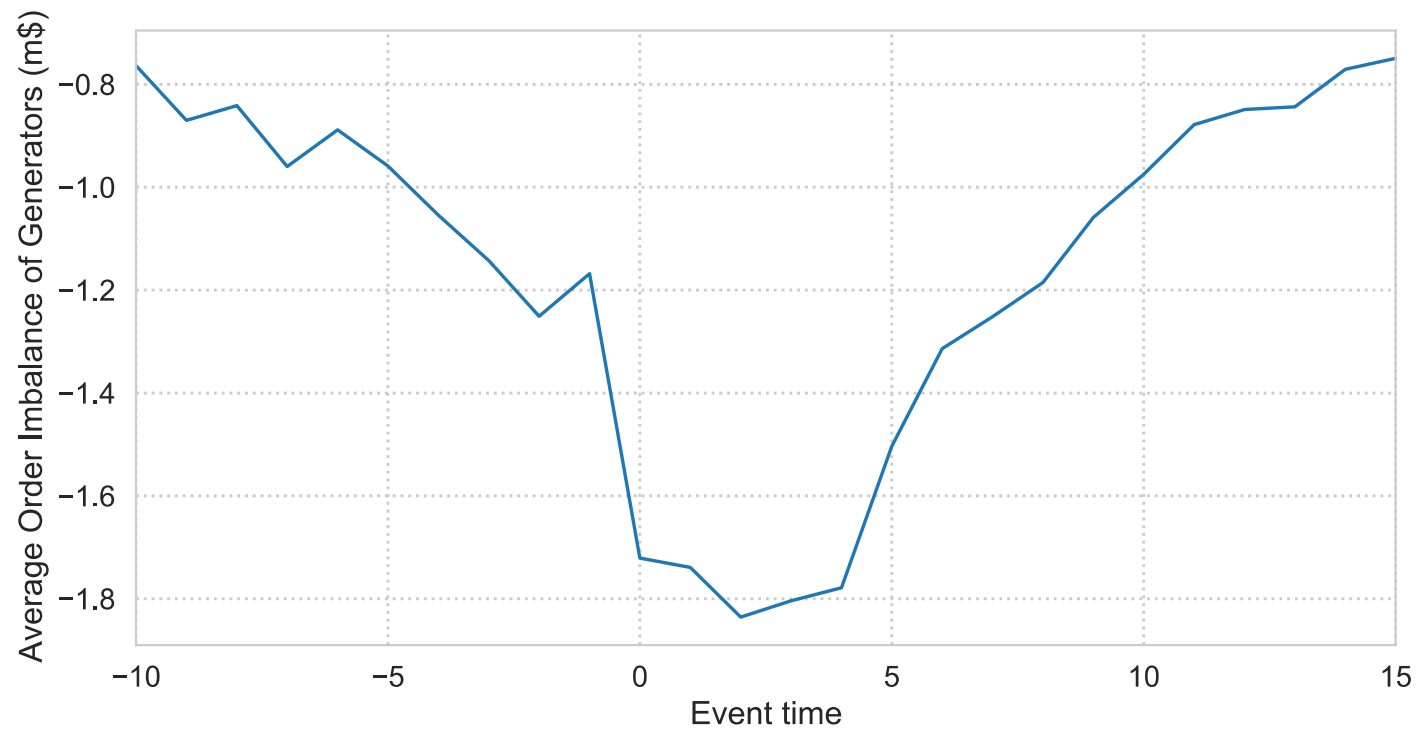

Figure 3: Liquidation Volume. The figure plots the average daily signed volume (i.e. order imbalance) of the fire sale originator on the fire sale stocks, expressed in Million Dollars.

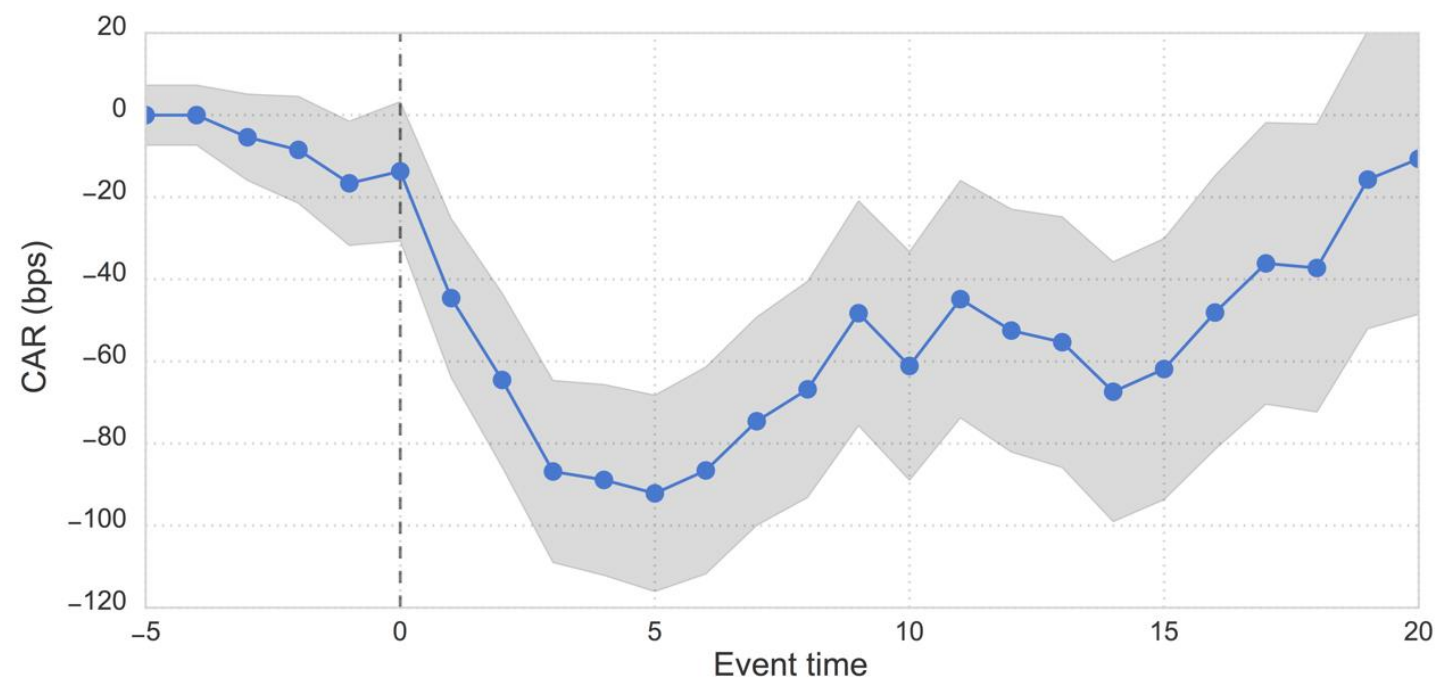

Figure 4: Price Pattern. The figure plots the average DGTW-adjusted cumulative returns for the stocks sold during the fire sales along with $95 \%$ confidence bands. 


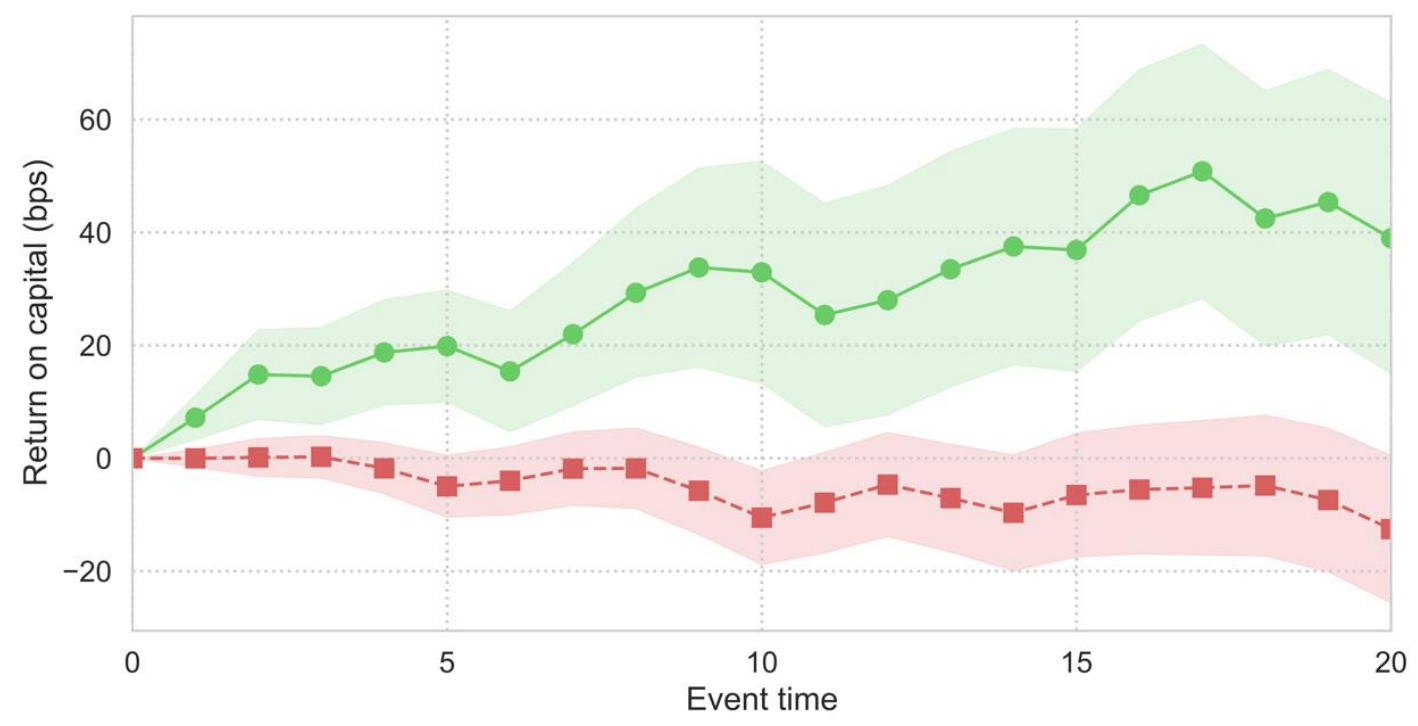

Figure 5: Profitability of Predatory Trades. The figure plots the profits of the managers that are best clients of the aware (green solid line with circles) and unaware (red dashed line with squares) brokers during the fire sale events.

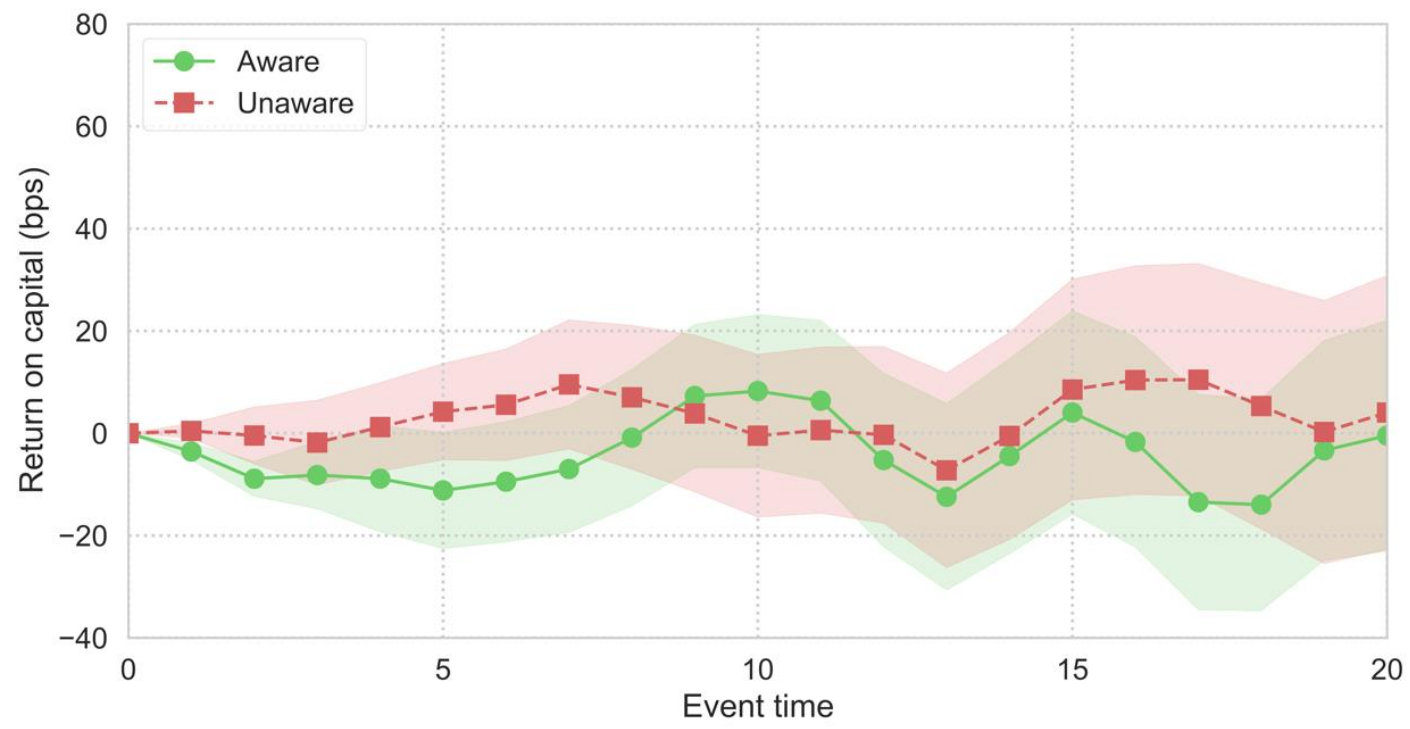

Figure 6: Placebo Test. The figure plots the profits of the managers that are best clients of the aware (green solid line with circles) and unaware (red dashed line with squares) brokers during random event windows other than the actual fire sales employed in the analysis. 


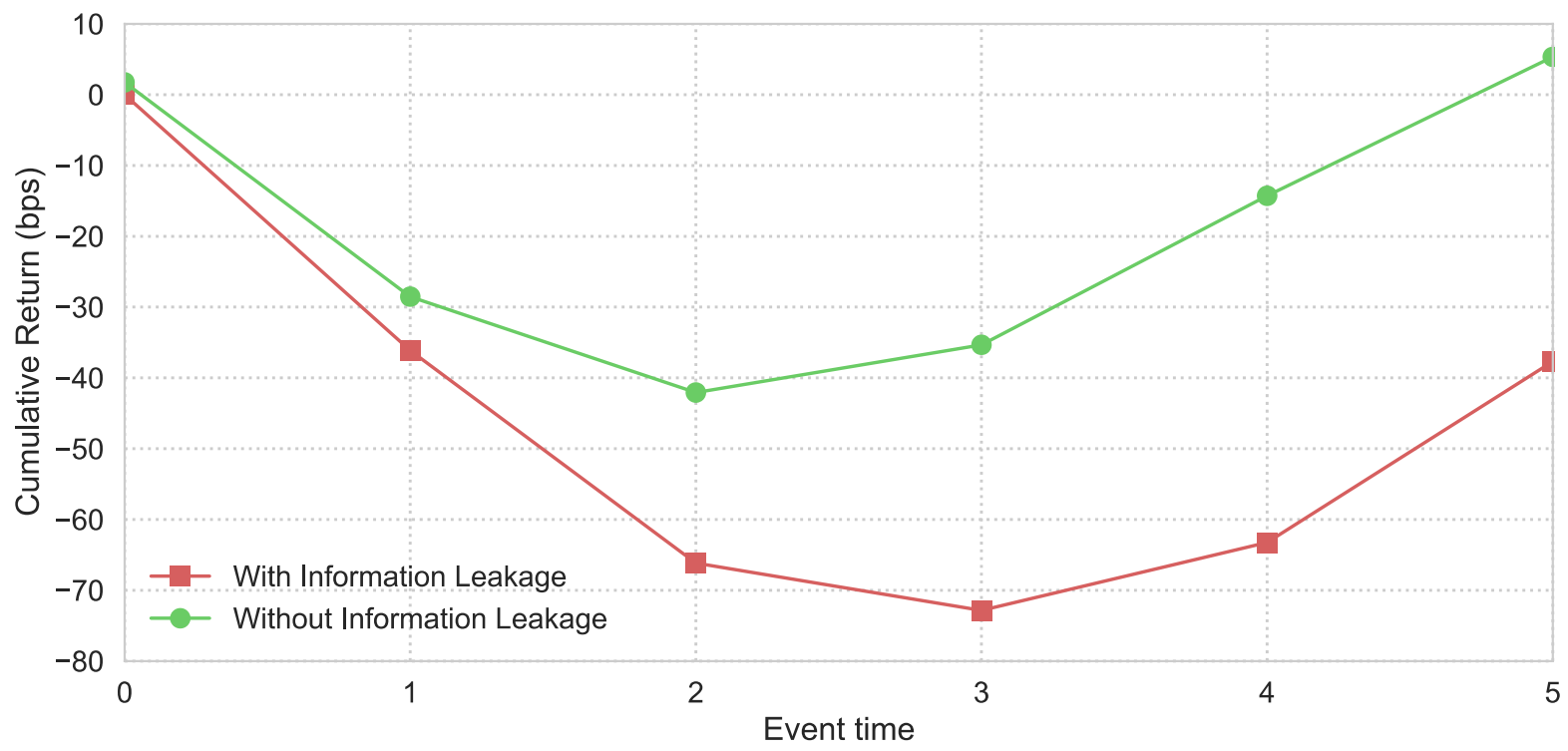

Figure 7: Price Paths with and without Information Leakage. The figure plots the cumulative return of the fire sale stocks during fire sale events involving at least one aware broker. The red line with squares represents the cumulative return averaged across stocks and events in which aware brokers are present. The green line with circles represents the cumulative return averaged across stocks and events in which no aware brokers are present. The series are based on estimates from a regression specification similar to the one reported in Table 12, but run on daily observations. 
Table 1

\section{Summary Statistics}

Panel A and Panel B report summary statistics for the 385 fire sale events identified by our methodology. In Panel C we regress the amount sold of each stock as a fraction of the total fire sale volume on a set of stocks characteristics. Standard errors are clustered at the event level. T-stats are reported in parentheses. Asterisks denote significance levels $(* * *=1 \%, * *=5 \%, *=10 \%)$. To identify fire sale events, we start by computing the signed volume Z-score $Z_{t}^{m}$ for each manager $m$ on day $t$ as $\mathrm{Z}_{\mathrm{t}}^{\mathrm{m}}=\left(D V o l_{t}^{m}-E\left(D V o l_{t}^{m}\right)\right) / \sigma\left(D V o l_{t}^{m}\right)$, where $D V o l_{t}^{m}$ is the portfolio level dollar volume traded by manager $m$ on day $t$, and its mean and standard deviation are estimated over a rolling window of 120 trading days ending one week before day $t$. Then, at the portfolio level, we define manger $m$ as liquidating if $Z_{t}^{m}$ is below 0.25 for at least 5 trading days in a row. Next, we impose a filter at the stock level: for stock $j$ to enter the fire sale basket we require that the volume traded by the manager is above $1 \%$ of the CRSP daily volume for at least 4 of the fire sale days. Finally, we keep events in which at least 10 stocks are sold by the liquidating fund.

Panel A: Fire Sale Events

\begin{tabular}{|c|c|c|c|c|c|c|c|c|}
\hline & Unit & Obs & Mean & S.D. & $25 \%$ & $50 \%$ & $75 \%$ & $90 \%$ \\
\hline Dollar Volume & Million Dollars & 385 & -377.062 & 534.635 & -503.571 & -177.461 & -50.544 & -18.244 \\
\hline Fraction of Portfolio & Percentage & 385 & $9.164 \%$ & $23.921 \%$ & $1.224 \%$ & $2.274 \%$ & $5.879 \%$ & $15.828 \%$ \\
\hline Number of Stocks & & 385 & 21.917 & 10.090 & 13 & 18 & 29 & 38 \\
\hline Event Length & Trading Days & 385 & 5.766 & 1.439 & 5 & 5 & 6 & 7 \\
\hline Number of Brokers & & 385 & 28.803 & 16.095 & 18 & 27 & 39 & 52 \\
\hline Number of Aware Brokers & & 385 & 1.694 & 0.968 & 1 & 2 & 2 & 3 \\
\hline
\end{tabular}

Panel B: Fire Sale Stocks

\begin{tabular}{|c|c|c|c|c|c|c|c|c|}
\hline & Unit & Obs & Mean & S.D. & $25 \%$ & $50 \%$ & $75 \%$ & $90 \%$ \\
\hline Dollar Volume & Million Dollars & 8438 & -17.204 & 20.305 & -23.401 & -11.246 & -3.542 & -1.366 \\
\hline CRSP volume ratio & Percentage & 8438 & $-14.576 \%$ & $16.000 \%$ & $-18.749 \%$ & $-9.922 \%$ & $-4.585 \%$ & $-2.409 \%$ \\
\hline Number of Brokers & & 8438 & 5.737 & 5.039 & 2 & 4 & 8 & 13 \\
\hline Number of Aware Brokers & & 8438 & 0.522 & 0.603 & 0 & 0 & 1 & 1 \\
\hline
\end{tabular}

Panel C: Fire Sale Stocks Selection

\begin{tabular}{|c|c|c|c|c|c|c|}
\hline \multirow[t]{2}{*}{ Dependent Variable } & \multicolumn{6}{|c|}{ Amount Sold as a Fraction of the Fire Sale } \\
\hline & (1) & (2) & (3) & (4) & (5) & (6) \\
\hline Portfolio Weight & $\begin{array}{c}1.863 * * * \\
(6.522)\end{array}$ & $\begin{array}{c}1.830 * * * \\
(6.427)\end{array}$ & $\begin{array}{c}1.319 * * * \\
(5.875)\end{array}$ & $\begin{array}{c}1.805^{* * *} * \\
(6.540)\end{array}$ & $\begin{array}{c}1.301 * * * \\
(5.815)\end{array}$ & $\begin{array}{c}1.318 * * * \\
(5.842)\end{array}$ \\
\hline Amihud Ratio & & $\begin{array}{c}-0.691 * * * \\
(-8.419)\end{array}$ & & & $\begin{array}{c}-0.486 * * * \\
(-6.579)\end{array}$ & $\begin{array}{c}-0.506 * * * \\
(-6.775)\end{array}$ \\
\hline Market Cap & & & $\begin{array}{c}2.614 * * * \\
(11.580)\end{array}$ & & $\begin{array}{c}2.427 * * * \\
(10.926)\end{array}$ & $\begin{array}{c}2.441 * * * \\
(10.977)\end{array}$ \\
\hline Volatility & & & & $\begin{array}{c}-6.698 * * * \\
(-12.549)\end{array}$ & $\begin{array}{c}-3.838 * * * \\
(-7.296)\end{array}$ & $\begin{array}{c}-3.394 * * * \\
(-6.438)\end{array}$ \\
\hline One Month Return & & & & & & $\begin{array}{c}0.112 \\
(0.981)\end{array}$ \\
\hline Six Months Return & & & & & & $\begin{array}{l}0.209 * \\
(1.741)\end{array}$ \\
\hline One Year Return & & & & & & $\begin{array}{c}0.340 * * * \\
(2.783)\end{array}$ \\
\hline Observations & 7,948 & 7,948 & 7,948 & 7,948 & 7,948 & 7,948 \\
\hline R-squared & 0.134 & 0.142 & 0.237 & 0.164 & 0.253 & 0.257 \\
\hline Time FE & Yes & Yes & Yes & Yes & Yes & Yes \\
\hline Manager FE & Yes & Yes & Yes & Yes & Yes & Yes \\
\hline Event FE & Yes & Yes & Yes & Yes & Yes & Yes \\
\hline
\end{tabular}


Table 2

\section{Predatory Behavior and Broker Awareness}

The table reports results on the likelihood of a broker to attract predatory trades. The regressions are run at the ticketlevel, excluding trades by managers originating the fire-sale of interest or another overlapping fire-sale. In Columns (1)-(4), the dependent variable is a dummy indicating predation, i.e. it takes value one when the trade is in the same direction of the volume by the liquidating fund for that stock on that day (i.e. it is a sell trade), while it equals zero if the trade is in the opposite direction (i.e. a buy trade), or if the liquidating fund is not trading that stock on that particular day. The independent variable Aware is a dummy, defined at the event-broker-stock-day level, indicating that the broker is aware of the fire sale happening on the traded stock on that day. Precisely, this means that for broker $B$, stock $j$ on day $t$ the variable $A w a B r o_{t}^{B j}=0.5 \times A w a E v_{t}^{B}\left(1+A w a S t o_{t}^{B j}\right)$ is above the $10 \%$ threshold. Here $A w a S t o=t_{t}^{B j}$ is the stock-level awareness, defined as the ratio between the turnover intermediated by $B$ on stock $j$ up to day $t$ and the total turnover on stock $i$ up to day $t$ (over all the active brokers). $A w a E v_{t}^{B}$ is the event-level awareness, i.e. the ratio between the turnover intermediated by $B$ on all the fire sale stocks up to day $t$ and the total turnover on all the fire sale stocks up to that day (over all the active brokers). In Columns (5)-(8), we weight the above described dependent variable by the volume of the trade as a fraction of market capitalization, standardized. Standard errors are clustered at the broker level. T-stats are reported in parentheses. Asterisks denote significance levels $(* * *=1 \%, * *=5 \%, *=10 \%)$.

\begin{tabular}{lccccccccc}
\hline Dependent Variable & \multicolumn{3}{c}{ Probability of Predation } & \multicolumn{5}{c}{ Volume of Predatory Trades } \\
\hline & $(1)$ & $(2)$ & $(3)$ & $(4)$ & $(5)$ & $(6)$ & $(7)$ & $(8)$ \\
\hline \multirow{2}{*}{ Aware } & & & & & & & & \\
& $0.091^{* * *}$ & $0.078^{* * *}$ & $0.074 * * *$ & $0.060^{* * *}$ & $0.171^{* * *}$ & $0.160^{* *}$ & $0.166^{* *}$ & $0.140^{* * *}$ \\
& $(4.751)$ & $(4.848)$ & $(4.634)$ & $(4.642)$ & $(2.608)$ & $(2.530)$ & $(2.508)$ & $(3.811)$ \\
Time Fixed Effects & & & & & & & & \\
Manager Fixed Effects & Yes & Yes & Yes & Yes & Yes & Yes & Yes & Yes \\
Broker Fixed Effects & & Yes & Yes & Yes & & Yes & Yes & Yes \\
Event Fixed Effects & & & Yes & Yes & & & Yes & Yes \\
& & & & Yes & & & & Yes \\
Observations & 496,729 & 496,685 & 496,555 & 496,555 & 489,323 & 489,281 & 489,148 & 489,148 \\
R-squared & 0.076 & 0.103 & 0.107 & 0.120 & 0.020 & 0.028 & 0.032 & 0.037 \\
\hline
\end{tabular}


Table 3

Persistence of Broker-Client Relationship

The table reports results on the persistence of our proxies for the strength of the broker-manager relationship, defined as follows:

(1) Dummy variable indicating that the manager generated at least $5 \%$ of the total volume intermediated by the broker over the previous semester

(2) Dummy variable indicating that the manager is in the top decile of managers ranked by the volume generated for the broker over the previous semester

(3) Dummy variable indicating that the manager is in the top decile of managers ranked by the commission paid to the broker over the previous semester

(4) Continuous variable with values in the unit interval, ranking of the manager in terms of the volume generated for the broker over the previous semester

(5) Continuous variable with values on the unit interval, ranking of the manager in terms of the commission paid to the broker over the previous semester.

For each of the above proxies of relationship strength, we run a panel regression of the proxy onto its one-month lagged value. The panel is not fully balanced due to the fact that not all months record a broker-manager interaction. Thus, we fill with zeros the manager-broker pairs for which there is no transaction but for which at least one transaction with another manager or broker is present in Ancerno in that period. Manager and broker fixed-effects are included in the regression. Stardard errors are double-clustered at the manager- and broker-level. T-stats are reported in parentheses. Asterisks denote significance levels $(* * *=1 \%, * *=5 \%, *=10 \%)$

\begin{tabular}{|c|c|c|c|c|c|}
\hline \multirow[t]{2}{*}{ Dependent variable } & \multicolumn{5}{|c|}{ Best Client } \\
\hline & (1) & (2) & (3) & (4) & (5) \\
\hline Best clients proxy & Volume above $5 \%$ & Top Decile of Volume & $\begin{array}{l}\text { Top Decile of } \\
\text { Commissions }\end{array}$ & $\begin{array}{c}\text { Ranking based on } \\
\text { Volume }\end{array}$ & $\begin{array}{l}\text { Ranking based on } \\
\text { Commissions Paid }\end{array}$ \\
\hline Best Client (Lag) & $\begin{array}{l}0.353 * * * \\
(11.451)\end{array}$ & $\begin{array}{l}0.421 * * * \\
(14.028)\end{array}$ & $\begin{array}{c}0.408 * * * \\
(13.994)\end{array}$ & $\begin{array}{l}0.384 * * * \\
(16.262)\end{array}$ & $\begin{array}{c}0.377 * * * \\
(16.453)\end{array}$ \\
\hline Manager Fixed Effects & Yes & Yes & Yes & Yes & Yes \\
\hline Broker Fixed Effects & Yes & Yes & Yes & Yes & Yes \\
\hline Observations & $12,873,238$ & $12,873,238$ & $12,873,238$ & $12,873,238$ & $12,873,238$ \\
\hline R-squared & 0.132 & 0.181 & 0.184 & 0.157 & 0.158 \\
\hline
\end{tabular}


Table 4

Probability of Predation and Broker-Client Relationship Strength

The table presents evidence of the effect of broker-client relationship strength on the probability of predatory behavior. The regressions are run at the ticket-level, excluding trades by managers originating the fire-sale of interest or another overlapping fire-sale. In all specifications the dependent variable is a dummy indicating predation, i.e. it takes value one when the trade is in the same direction of the volume by the liquidating fund for that stock on that day (i.e. a sell trade), while it equals zero if the trade is in the opposite direction (i.e. a buy trade) or if the liquidating fund is not trading that stock on that particular day. In Panel A we regress the dependent variable on the dummy Best Client indicating if the manager is among the best clients of the broker intermediating the transcation, the dummy Liquidation Period indicating the first 5 days of the fire sale, and the interaction of the two dummies. We consider all trades on stock $j$ intermediated by brokers that eventually become aware that the stock is subject to fire sale pressure, i.e. brokers $B$ for which $\max _{t \in[0,4]}\left(A w a B r o_{t}^{B j}\right)=1$, where $A w a B r o_{t}^{B j}$ is defined as above. The regression is run on a sample that includes five days before the fire sale and five days from the start of the fire sale, defined as the first day in which our liquidation measure crosses the threshold. In Panel B we regress the dependent variable on the triple interaction of the following dummies: Aware Broker indicating if the broker is aware, Best Client indicating if the manager is among the best clients of the broker intermediating the transcation, and Liquidation Period indicating the first 5 days of the fire sale. We include manager, broker, stock, day and event fixed effects. Standard errors are clustered at the event-stock-manager level and T-stats are reported in parentheses. Asterisks denote significance levels $(* * *=1 \%$, $* *=5 \%, *=10 \%)$

Panel A: Difference in Differences

\begin{tabular}{|c|c|c|c|c|c|}
\hline \multirow[t]{2}{*}{ Dependent variable } & \multicolumn{5}{|c|}{ Probability of Predation } \\
\hline & (1) & (2) & (3) & (4) & (5) \\
\hline Best clients proxy & Volume above 5\% & Top Decile of Volume & $\begin{array}{l}\text { Top Decile of } \\
\text { Commissions }\end{array}$ & $\begin{array}{l}\text { Ranking based on } \\
\text { Volume }\end{array}$ & $\begin{array}{l}\text { Ranking based on } \\
\text { Commissions Paid }\end{array}$ \\
\hline Best Client $\times$ Liquidation Period & $\begin{array}{c}0.031 * * * \\
(5.491)\end{array}$ & $\begin{array}{c}0.020 * * * \\
(5.751)\end{array}$ & $\begin{array}{c}0.022 * * * \\
(6.286)\end{array}$ & $\begin{array}{c}0.027 * * * \\
(5.917)\end{array}$ & $\begin{array}{c}0.024 * * * \\
(5.503)\end{array}$ \\
\hline Best Client & $\begin{array}{c}-0.008 \\
(-0.725)\end{array}$ & $\begin{array}{l}-0.009 \\
(-1.023)\end{array}$ & $\begin{array}{c}0.007 \\
(0.842)\end{array}$ & $\begin{array}{c}0.017 \\
(1.088)\end{array}$ & $\begin{array}{l}-0.016 \\
(-1.109)\end{array}$ \\
\hline Liquidation Period & $\begin{array}{l}0.010^{*} \\
(1.759)\end{array}$ & $\begin{array}{c}0.007 \\
(1.372)\end{array}$ & $\begin{array}{c}0.007 \\
(1.357)\end{array}$ & $\begin{array}{c}-0.007 \\
(-1.175)\end{array}$ & $\begin{array}{l}-0.005 \\
(-0.794)\end{array}$ \\
\hline Time Fixed Effects & Yes & Yes & Yes & Yes & Yes \\
\hline Manager Fixed Effects & Yes & Yes & Yes & Yes & Yes \\
\hline Event Fixed Effects & Yes & Yes & Yes & Yes & Yes \\
\hline Stock Fixed Effects & Yes & Yes & Yes & Yes & Yes \\
\hline Broker Fixed Effects & Yes & Yes & Yes & Yes & Yes \\
\hline Observations & 147,667 & 147,667 & 147,667 & 147,667 & 147,667 \\
\hline R-squared & 0.287 & 0.287 & 0.287 & 0.287 & 0.287 \\
\hline
\end{tabular}


Panel B: Triple Interaction

\begin{tabular}{|c|c|c|c|c|c|}
\hline \multirow[t]{2}{*}{ Dependent variable } & \multicolumn{5}{|c|}{ Probability of Predation } \\
\hline & (1) & (2) & (3) & (4) & (5) \\
\hline Best clients proxy & Volume above $5 \%$ & Top Decile of Volume & $\begin{array}{l}\text { Top Decile of } \\
\text { Commissions }\end{array}$ & $\begin{array}{c}\text { Ranking based on } \\
\text { Volume }\end{array}$ & $\begin{array}{l}\text { Ranking based on } \\
\text { Commissions Paid }\end{array}$ \\
\hline Aware Broker $\times$ Best Client $\times$ Liquidation Period & $\begin{array}{c}0.114 * * * \\
(3.935)\end{array}$ & $\begin{array}{l}0.044 * * \\
(2.215)\end{array}$ & $\begin{array}{l}0.053 * * \\
(2.555)\end{array}$ & $\begin{array}{l}0.042 * * \\
(2.094)\end{array}$ & $\begin{array}{l}0.040 * * \\
(1.963)\end{array}$ \\
\hline Best Client $\times$ Liquidation Period & $\begin{array}{c}-0.049 * * * \\
(-2.768)\end{array}$ & $\begin{array}{c}-0.020 * * * \\
(-5.655)\end{array}$ & $\begin{array}{c}-0.015^{* * *} \\
(-4.209)\end{array}$ & $\begin{array}{c}-0.025 * * * \\
(-4.688)\end{array}$ & $\begin{array}{c}-0.019 * * * \\
(-3.659)\end{array}$ \\
\hline Aware Broker $\times$ Liquidation Period & $\begin{array}{c}0.008 \\
(0.809)\end{array}$ & $\begin{array}{c}0.001 \\
(0.062)\end{array}$ & $\begin{array}{c}0.000 \\
(0.041)\end{array}$ & $\begin{array}{l}-0.009 \\
(-0.682)\end{array}$ & $\begin{array}{l}-0.006 \\
(-0.414)\end{array}$ \\
\hline Best Client $\times$ Aware Broker & $\begin{array}{l}-0.020 \\
(-0.816)\end{array}$ & $\begin{array}{l}-0.038 * * \\
(-2.550)\end{array}$ & $\begin{array}{l}-0.034 * * \\
(-2.254)\end{array}$ & $\begin{array}{c}-0.040 * * * \\
(-2.617)\end{array}$ & $\begin{array}{c}-0.033 * * \\
(-2.132)\end{array}$ \\
\hline Best Client & $\begin{array}{c}0.010 \\
(0.927)\end{array}$ & $\begin{array}{l}0.007 * * \\
(2.158)\end{array}$ & $\begin{array}{l}0.008 * * \\
(2.402)\end{array}$ & $\begin{array}{c}0.025 * * * \\
(3.962)\end{array}$ & $\begin{array}{c}0.025^{* * * *} \\
(4.320)\end{array}$ \\
\hline Aware Broker & $\begin{array}{c}0.035 * * * \\
(4.872)\end{array}$ & $\begin{array}{c}0.047 * * * \\
(5.834)\end{array}$ & $\begin{array}{l}0.045^{* * * *} \\
(5.669)\end{array}$ & $\begin{array}{c}0.057 * * * \\
(5.700)\end{array}$ & $\begin{array}{c}0.052^{* * * *} \\
(5.318)\end{array}$ \\
\hline Liquidation Period & $\begin{array}{l}0.105 * * * \\
(51.364)\end{array}$ & $\begin{array}{l}0.114^{* * * *} \\
(44.369)\end{array}$ & $\begin{array}{l}0.111 * * * \\
(44.222)\end{array}$ & $\begin{array}{l}0.123 * * * \\
(26.837)\end{array}$ & $\begin{array}{l}0.118^{* * * *} \\
(27.032)\end{array}$ \\
\hline Time Fixed Effects & Yes & Yes & Yes & Yes & Yes \\
\hline Manager Fixed Effects & Yes & Yes & Yes & Yes & Yes \\
\hline Event Fixed Effects & Yes & Yes & Yes & Yes & Yes \\
\hline Stock Fixed Effects & Yes & Yes & Yes & Yes & Yes \\
\hline Broker Fixed Effects & Yes & Yes & Yes & Yes & Yes \\
\hline Observations & 478,427 & 478,427 & 478,427 & 478,427 & 478,427 \\
\hline R-squared & 0.114 & 0.114 & 0.114 & 0.114 & 0.114 \\
\hline
\end{tabular}


Table 5

Robustness: Excluding Bad News

The table reports results on a first set robustness checks on the baseline results presented in Table 4 . In the specifications of Panel A we exclude the fire-sale events happening during NBER recession periods, which in our sample include the burst of the dot-com bubble (March 2001 - November 2001) and the global financial crisis (December 2007 - June 2009). In the specifications of Panel B we exclude stocks subject to negative fundamental news in a window of 5 days before and after the start of the fire-sale event, as proxied by (i) negative earning surprises, (ii) Raven Pack news index in the bottom quartile, (iii) negative analyst reccomendation changes. We include manager, broker, stock, day and event fixed effects and we cluster standard errors at the event-stock-manager level. T-stats are reported in parentheses. Asterisks denote significance levels $(* * *=1 \%, * *=5 \%, *=10 \%)$

Panel A: Excluding NBER Recessions Periods

\begin{tabular}{|c|c|c|c|c|c|}
\hline \multirow[t]{2}{*}{ Dependent variable } & \multicolumn{5}{|c|}{ Probability of Predation } \\
\hline & (1) & $(2)$ & (3) & (4) & (5) \\
\hline Best clients proxy & Volume above $5 \%$ & Top Decile of Volume & $\begin{array}{l}\text { Top Decile of } \\
\text { Commissions }\end{array}$ & $\begin{array}{c}\text { Ranking based on } \\
\text { Volume }\end{array}$ & $\begin{array}{l}\text { Ranking based on } \\
\text { Commissions Paid }\end{array}$ \\
\hline Best Client $\times$ Liquidation Period & $\begin{array}{l}0.031 * * * \\
(5.025)\end{array}$ & $\begin{array}{l}0.020 * * * \\
(5.233)\end{array}$ & $\begin{array}{l}0.021 * * * \\
(5.632)\end{array}$ & $\begin{array}{l}0.023 * * * \\
(4.874)\end{array}$ & $\begin{array}{c}0.020 * * * \\
(4.382)\end{array}$ \\
\hline Best Client & $\begin{array}{l}-0.001 \\
(-0.057)\end{array}$ & $\begin{array}{l}-0.010 \\
(-0.943)\end{array}$ & $\begin{array}{c}0.007 \\
(0.762)\end{array}$ & $\begin{array}{c}0.016 \\
(0.886)\end{array}$ & $\begin{array}{l}-0.012 \\
(-0.741)\end{array}$ \\
\hline Liquidation Period & $\begin{array}{l}0.009 * \\
(1.665)\end{array}$ & $\begin{array}{c}0.007 \\
(1.319)\end{array}$ & $\begin{array}{c}0.007 \\
(1.313)\end{array}$ & $\begin{array}{l}-0.005 \\
(-0.780)\end{array}$ & $\begin{array}{l}-0.002 \\
(-0.377)\end{array}$ \\
\hline Time Fixed Effects & Yes & Yes & Yes & Yes & Yes \\
\hline Manager Fixed Effects & Yes & Yes & Yes & Yes & Yes \\
\hline Event Fixed Effects & Yes & Yes & Yes & Yes & Yes \\
\hline Stock Fixed Effects & Yes & Yes & Yes & Yes & Yes \\
\hline Broker Fixed Effects & Yes & Yes & Yes & Yes & Yes \\
\hline Observations & 125,899 & 125,899 & 125,899 & 125,899 & 125,899 \\
\hline R-squared & 0.302 & 0.302 & 0.302 & 0.302 & 0.302 \\
\hline
\end{tabular}

Panel B: Excluding Negative News

\begin{tabular}{|c|c|c|c|c|c|}
\hline \multirow[t]{2}{*}{ Dependent variable } & \multicolumn{5}{|c|}{ Probability of Predation } \\
\hline & (1) & (2) & (3) & (4) & (5) \\
\hline Best clients proxy & Volume above $5 \%$ & Top Decile of Volume & $\begin{array}{l}\text { Top Decile of } \\
\text { Commissions }\end{array}$ & $\begin{array}{c}\text { Ranking based on } \\
\text { Volume }\end{array}$ & $\begin{array}{l}\text { Ranking based on } \\
\text { Commissions Paid }\end{array}$ \\
\hline Best Client $\times$ Liquidation Period & $\begin{array}{c}0.032 * * * \\
(5.443)\end{array}$ & $\begin{array}{c}0.020 * * * \\
(5.631)\end{array}$ & $\begin{array}{c}0.021 * * * \\
(5.829)\end{array}$ & $\begin{array}{c}0.024 * * * \\
(5.091)\end{array}$ & $\begin{array}{c}0.022 * * * \\
(4.701)\end{array}$ \\
\hline Best Client & $\begin{array}{l}-0.009 \\
(-0.824)\end{array}$ & $\begin{array}{l}-0.012 \\
(-1.178)\end{array}$ & $\begin{array}{c}0.007 \\
(0.681)\end{array}$ & $\begin{array}{c}0.019 \\
(1.172)\end{array}$ & $\begin{array}{c}-0.012 \\
(-0.799)\end{array}$ \\
\hline Liquidation Period & $\begin{array}{c}0.009 \\
(1.629)\end{array}$ & $\begin{array}{c}0.007 \\
(1.244)\end{array}$ & $\begin{array}{c}0.007 \\
(1.269)\end{array}$ & $\begin{array}{l}-0.005 \\
(-0.884)\end{array}$ & $\begin{array}{c}-0.003 \\
(-0.542)\end{array}$ \\
\hline Time Fixed Effects & Yes & Yes & Yes & Yes & Yes \\
\hline Manager Fixed Effects & Yes & Yes & Yes & Yes & Yes \\
\hline Event Fixed Effects & Yes & Yes & Yes & Yes & Yes \\
\hline Stock Fixed Effects & Yes & Yes & Yes & Yes & Yes \\
\hline Broker Fixed Effects & Yes & Yes & Yes & Yes & Yes \\
\hline Observations & 134,248 & 134,248 & 134,248 & 134,248 & 134,248 \\
\hline R-squared & 0.292 & 0.292 & 0.292 & 0.292 & 0.292 \\
\hline
\end{tabular}


Table 6

Robustness: Excluding Underperforming Stocks

The table reports results on a set of robustness checks on the baseline results presented in Table 4. In the specifications of Panel A we exclude stocks expriencig negative returns in a window of 10 days preceding the start of the fire-sale event. In Panel B, we exclude stocks with high short interest in the 2 weeks preceding the fire sale event, as proxied by a value of utilisation ratio, computed using data from Markit as shares on loan / shares available from lending, in the top quartile of the cross-sectional distribution in the CRSP universe. We include manager, broker, stock, day and event fixed effects and we cluster standard errors at the event-stock-manager level. T-stats are reported in parentheses. Asterisks denote significance levels $(* * *=1 \%, * *=5 \%, *=10 \%)$

Panel A: Excluding Negative Momentum Stocks

\begin{tabular}{|c|c|c|c|c|c|}
\hline \multirow[t]{2}{*}{ Dependent variable } & \multicolumn{5}{|c|}{ Probability of Predation } \\
\hline & (1) & (2) & (3) & (4) & (5) \\
\hline Best clients proxy & Volume above $5 \%$ & Top Decile of Volume & $\begin{array}{l}\text { Top Decile of } \\
\text { Commissions }\end{array}$ & $\begin{array}{c}\text { Ranking based on } \\
\text { Volume }\end{array}$ & $\begin{array}{l}\text { Ranking based on } \\
\text { Commissions Paid }\end{array}$ \\
\hline Best Client $\times$ Liquidation Period & $\begin{array}{c}0.032 * * * \\
(5.633)\end{array}$ & $\begin{array}{c}0.021 * * * \\
(5.809)\end{array}$ & $\begin{array}{c}0.024 * * * \\
(6.698)\end{array}$ & $\begin{array}{c}0.025 * * * \\
(5.147)\end{array}$ & $\begin{array}{c}0.022 * * * \\
(4.809)\end{array}$ \\
\hline Best Client & $\begin{array}{l}-0.001 \\
(-0.123)\end{array}$ & $\begin{array}{l}-0.004 \\
(-0.451)\end{array}$ & $\begin{array}{c}0.011 \\
(1.220)\end{array}$ & $\begin{array}{c}0.020 \\
(1.231)\end{array}$ & $\begin{array}{l}-0.011 \\
(-0.752)\end{array}$ \\
\hline Liquidation Period & $\begin{array}{c}0.009 \\
(1.608)\end{array}$ & $\begin{array}{c}0.007 \\
(1.276)\end{array}$ & $\begin{array}{c}0.007 \\
(1.234)\end{array}$ & $\begin{array}{l}-0.006 \\
(-0.857)\end{array}$ & $\begin{array}{l}-0.003 \\
(-0.526)\end{array}$ \\
\hline Time Fixed Effects & Yes & Yes & Yes & Yes & Yes \\
\hline Manager Fixed Effects & Yes & Yes & Yes & Yes & Yes \\
\hline Event Fixed Effects & Yes & Yes & Yes & Yes & Yes \\
\hline Stock Fixed Effects & Yes & Yes & Yes & Yes & Yes \\
\hline Broker Fixed Effects & Yes & Yes & Yes & Yes & Yes \\
\hline Observations & 135,299 & 135,299 & 135,299 & 135,299 & 135,299 \\
\hline R-squared & 0.292 & 0.292 & 0.292 & 0.292 & 0.292 \\
\hline \multicolumn{6}{|c|}{ Panel B: Excluding High Short Interest Stocks } \\
\hline Dependent variable & \multicolumn{5}{|c|}{ Probability of Predation } \\
\hline & (1) & (2) & (3) & (4) & (5) \\
\hline Best clients proxy & Volume above $5 \%$ & Top Decile of Volume & $\begin{array}{l}\text { Top Decile of } \\
\text { Commissions }\end{array}$ & $\begin{array}{c}\text { Ranking based on } \\
\text { Volume }\end{array}$ & $\begin{array}{l}\text { Ranking based on } \\
\text { Commissions Paid }\end{array}$ \\
\hline Best Client $\times$ Liquidation Period & $\begin{array}{c}0.033^{* * * *} \\
(5.777)\end{array}$ & $\begin{array}{c}0.021 * * * \\
(5.958)\end{array}$ & $\begin{array}{c}0.022 * * * \\
(6.326)\end{array}$ & $\begin{array}{c}0.026 * * * \\
(5.625)\end{array}$ & $\begin{array}{c}0.023 * * * \\
(5.221)\end{array}$ \\
\hline Best Client & $\begin{array}{l}-0.002 \\
(-0.147)\end{array}$ & $\begin{array}{l}-0.008 \\
(-0.837)\end{array}$ & $\begin{array}{c}0.010 \\
(1.118)\end{array}$ & $\begin{array}{c}0.018 \\
(1.115)\end{array}$ & $\begin{array}{l}-0.014 \\
(-0.957)\end{array}$ \\
\hline Liquidation Period & $\begin{array}{c}0.007 \\
(1.330)\end{array}$ & $\begin{array}{c}0.005 \\
(0.955)\end{array}$ & $\begin{array}{l}0.005 \\
(0.957)\end{array}$ & $\begin{array}{l}-0.008 \\
(-1.364)\end{array}$ & $\begin{array}{l}-0.006 \\
(-1.000)\end{array}$ \\
\hline Time Fixed Effects & Yes & Yes & Yes & Yes & Yes \\
\hline Manager Fixed Effects & Yes & Yes & Yes & Yes & Yes \\
\hline Event Fixed Effects & Yes & Yes & Yes & Yes & Yes \\
\hline Stock Fixed Effects & Yes & Yes & Yes & Yes & Yes \\
\hline Broker Fixed Effects & Yes & Yes & Yes & Yes & Yes \\
\hline Observations & 142,027 & 142,027 & 142,027 & 142,027 & 142,027 \\
\hline R-squared & 0.290 & 0.290 & 0.290 & 0.290 & 0.290 \\
\hline
\end{tabular}


Table 7

Evidence of Predation on Multiple Stocks

The table reports results on the number of stocks experiencing predatory pressure. For each fire sale event we consider the basket of liquidated stocks, and for each manager actively trading at least one stock in the basket we count the number of stocks traded in the same direction of the fire sale originator. In Panel A, we consider event-manager observations and we regress the number of predated stocks on best client proxies. These are constructed by interacting the original best client proxies with the broker awareness dummy at the ticket-level, and then by taking the maximum value at the event-manager level. In Panel B, we repeat the exercise by adopting as dependent variable the fraction of predated stocks relative to the stocks in the fire sale basket. Event, manager and day fixed effects are included in the regressions and standard errors are double clustered at the manager and event level. T-stats are reported in parentheses. Asterisks denote significance levels $(* * *=1 \%, * *=5 \%, *=10 \%)$

Panel A: Number of stocks

\begin{tabular}{|c|c|c|c|c|c|}
\hline \multirow[t]{2}{*}{ Dependent variable } & \multicolumn{5}{|c|}{ Number of Predated Stocks } \\
\hline & (1) & $(2)$ & (3) & (4) & (5) \\
\hline Best clients proxy & Volume above $5 \%$ & Top Decile of Volume & $\begin{array}{l}\text { Top Decile of } \\
\text { Commissions }\end{array}$ & $\begin{array}{l}\text { Ranking based on } \\
\text { Volume }\end{array}$ & $\begin{array}{l}\text { Ranking based on } \\
\text { Commissions Paid }\end{array}$ \\
\hline Best Client & $\begin{array}{l}4.075 * * * \\
(5.744)\end{array}$ & $\begin{array}{l}3.206 * * * \\
(7.208)\end{array}$ & $\begin{array}{l}3.523 * * * \\
(8.342)\end{array}$ & $\begin{array}{l}2.829 * * * \\
(8.141)\end{array}$ & $\begin{array}{l}2.895 * * * \\
(8.341)\end{array}$ \\
\hline Time Fixed Effects & Yes & Yes & Yes & Yes & Yes \\
\hline Manager Fixed Effects & Yes & Yes & Yes & Yes & Yes \\
\hline Event Fixed Effects & Yes & Yes & Yes & Yes & Yes \\
\hline Observations & 17,096 & 17,096 & 17,096 & 17,096 & 17,096 \\
\hline R-squared & 0.419 & 0.424 & 0.426 & 0.427 & 0.428 \\
\hline
\end{tabular}

Panel B: Fraction of fire-sale basket

\begin{tabular}{|c|c|c|c|c|c|}
\hline \multirow[t]{2}{*}{ Dependent variable } & \multicolumn{5}{|c|}{ Fraction of Predated Stocks } \\
\hline & (1) & (2) & (3) & (4) & (5) \\
\hline Best clients proxy & Volume above $5 \%$ & Top Decile of Volume & $\begin{array}{l}\text { Top Decile of } \\
\text { Commissions }\end{array}$ & $\begin{array}{l}\text { Ranking based on } \\
\text { Volume }\end{array}$ & $\begin{array}{l}\text { Ranking based on } \\
\text { Commissions Paid }\end{array}$ \\
\hline Best Client & $\begin{array}{c}0.182 * * * \\
(5.864)\end{array}$ & $\begin{array}{c}0.131 * * * \\
(7.246)\end{array}$ & $\begin{array}{c}0.147 * * * \\
(7.905)\end{array}$ & $\begin{array}{c}0.113 * * * \\
(8.520)\end{array}$ & $\begin{array}{c}0.116^{* * *} \\
(8.675)\end{array}$ \\
\hline Time Fixed Effects & Yes & Yes & Yes & Yes & Yes \\
\hline Manager Fixed Effects & Yes & Yes & Yes & Yes & Yes \\
\hline Event Fixed Effects & Yes & Yes & Yes & Yes & Yes \\
\hline Observations & 17,096 & 17,096 & 17,096 & 17,096 & 17,096 \\
\hline R-squared & 0.486 & 0.489 & 0.492 & 0.491 & 0.492 \\
\hline
\end{tabular}


Table 8

Predators Position Reversal

The dependent variable is the fraction of sales in a given stock that a given manager subsequently reverses. In detail, in a given time period, either before or after the beginning of the fire sale, the percentage of position reversed for manager $m$ during event $e$ for stock $j$ is defined as the ratio $\operatorname{Rev}_{e, m, j}=$ BoughtBack $_{e, m, j} /$ Sold $_{\mathrm{e}, \mathrm{m}, \mathrm{j}}$, where Sold $_{\mathrm{e}, \mathrm{m}, \mathrm{j}}$ is the dollar sum of all sell orders in that period, and BoughtBack ${ }_{e, m, j}$ is the dollar sum of buy orders during the period, where we sum only the buy orders that are preceded by a negative cumulative order flow. We compute this measure around each fire sale event, for the event time periods Pre $=[-10,-1]$ and Post $=[1,10]$, considering all trades on stock $j$ intermediated by brokers who eventually become aware that the stock is subject to fire sale pressure. We then compare the percentage of position reversed by Best and Non-Best clients of the aware brokers before (Pre) and during (Post) the fire sale events. Liquidating funds are excluded from the sample. Time, stock and manager fixed-effects are added to the regression and standard errors are clustered at the manager level. T-stats are reported in parentheses. Asterisks denote significance levels $(* * *=1 \%, * *=5 \%, *=10 \%)$

\begin{tabular}{|c|c|c|c|c|c|}
\hline \multirow[t]{2}{*}{ Dependent variable } & \multicolumn{5}{|c|}{ Percentage of Positions Reversed } \\
\hline & (1) & (2) & (3) & (4) & (5) \\
\hline Best clients proxy & Volume above $5 \%$ & Top Decile of Volume & $\begin{array}{l}\text { Top Decile of } \\
\text { Commissions }\end{array}$ & $\begin{array}{c}\text { Ranking based on } \\
\text { Volume }\end{array}$ & $\begin{array}{l}\text { Ranking based on } \\
\text { Commissions Paid }\end{array}$ \\
\hline Best Client $\times$ Dummy $(0,10)$ & $\begin{array}{l}12.540 * \\
(1.791)\end{array}$ & $\begin{array}{l}16.513^{* * * *} \\
(2.794)\end{array}$ & $\begin{array}{l}15.807 * * * \\
(2.694)\end{array}$ & $\begin{array}{c}37.319 * * * \\
(2.881)\end{array}$ & $\begin{array}{c}28.802 * * * \\
(2.606)\end{array}$ \\
\hline Best Client & $\begin{array}{l}-4.253 \\
(-0.980)\end{array}$ & $\begin{array}{l}-7.922 \\
(-1.025)\end{array}$ & $\begin{array}{l}-5.707 \\
(-0.482)\end{array}$ & $\begin{array}{l}18.893 \\
(0.982)\end{array}$ & $\begin{array}{c}3.718 \\
(0.236)\end{array}$ \\
\hline Dummy $(0,10)$ & $\begin{array}{l}4.984^{*} \\
(1.959)\end{array}$ & $\begin{array}{c}3.573 \\
(0.859)\end{array}$ & $\begin{array}{c}4.256 \\
(1.043)\end{array}$ & $\begin{array}{l}-19.081 * \\
(-1.675)\end{array}$ & $\begin{array}{l}-11.349 \\
(-1.180)\end{array}$ \\
\hline Time Fixed Effects & Yes & Yes & Yes & Yes & Yes \\
\hline Stock Fixed Effects & Yes & Yes & Yes & Yes & Yes \\
\hline Manager Fixed Effects & Yes & Yes & Yes & Yes & Yes \\
\hline Observations & 14,817 & 12,556 & 12,556 & 12,556 & 12,556 \\
\hline R-squared & 0.121 & 0.282 & 0.282 & 0.283 & 0.282 \\
\hline
\end{tabular}


Table 9

Evidence from the 2003 Mutual Fund Scandal

We first match the list of 27 mutual fund families involved in the 2003 late-trading scandal with managers in our dataset and mark them as charged. We focus on daily transactions of the managers that are not involved in the scandal for a period of four years centered on the month of the announcement of the complaint by Spitzer (September 2003)

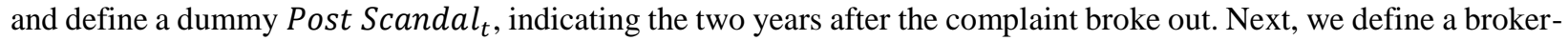
stock-day level dummy variable, Selling $g_{b, j, t}$, indicating that at least one of the charged funds is selling stock $j$ on day $t$ through broker $b$. Then, we define the dependent variable Probability of Predation as a dummy variable that equals 1 if a non-charged manager is selling stock $j$ on day $t$ through broker $b$. The dependent variable equals 0 if a noncharged manager trades on a different day, or on a different stock, or with a different broker. In a difference-indifferences setting, we regress the probability of predation on the interaction between Selling $g_{b, j, t}$ and the

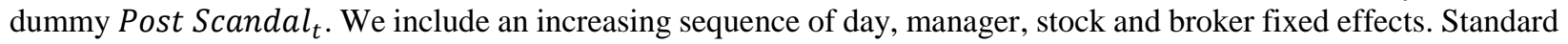
errors are clustered by manager-stock to and T-stats are reported in parentheses. Asterisks denote significance levels $(* * *=1 \%, * *=5 \%, *=10 \%)$

\begin{tabular}{|c|c|c|c|c|c|}
\hline \multirow[t]{2}{*}{ Dependent variable } & \multicolumn{5}{|c|}{ Probability of Predation } \\
\hline & (1) & (2) & (3) & (4) & (5) \\
\hline Selling $\times$ Post Scandal & $\begin{array}{c}0.043^{* * *} * \\
(11.409)\end{array}$ & $\begin{array}{c}0.048 * * * \\
(12.790)\end{array}$ & $\begin{array}{c}0.034 * * * \\
(9.259)\end{array}$ & $\begin{array}{c}0.030 * * * \\
(8.220)\end{array}$ & $\begin{array}{c}0.023 * * * \\
(6.339)\end{array}$ \\
\hline Selling & $\begin{array}{c}0.074 * * * \\
(23.090)\end{array}$ & $\begin{array}{l}0.071 * * * \\
(22.191)\end{array}$ & $\begin{array}{l}0.074 * * * \\
(22.444)\end{array}$ & $\begin{array}{c}0.076^{* * *} \\
(23.573)\end{array}$ & $\begin{array}{c}0.090 * * * \\
(28.319)\end{array}$ \\
\hline Post Scandal & $\begin{array}{c}-0.013 * * * \\
(-9.388)\end{array}$ & & & & \\
\hline Observations & $12,087,004$ & $12,087,004$ & $12,087,001$ & $12,086,863$ & $12,086,781$ \\
\hline R-squared & 0.001 & 0.013 & 0.068 & 0.076 & 0.082 \\
\hline Time Fixed Effects & & Yes & Yes & Yes & Yes \\
\hline Manager Fixed Effects & & & Yes & Yes & Yes \\
\hline Stock Fixed Effects & & & & Yes & Yes \\
\hline Broker Fixed Effects & & & & & Yes \\
\hline
\end{tabular}




\section{Table 10}

Hedge Funds vs. Other Institutions

The table reports results on the heterogeneity of the predatory behavior with respect to the characteristics of the clients. We run stock-level regressions with the same specification as in the baseline version of Table 4, but restricting to managers identified as hedge funds in Panel A and to the complementary set of other institutions in Panel B. We include manager, broker, stock, day, and event fixed effects and we cluster standard errors at the event-stock-manager level. T-stats are reported in parentheses. Asterisks denote significance levels $(* * *=1 \%, * *=5 \%, *=10 \%)$

Panel A: Hedge Funds Sample

\begin{tabular}{|c|c|c|c|c|c|}
\hline \multirow[t]{2}{*}{ Dependent variable } & \multicolumn{5}{|c|}{ Probability of Predation } \\
\hline & (1) & (2) & (3) & (4) & (5) \\
\hline Best clients proxy & Volume above $5 \%$ & Top Decile of Volume & $\begin{array}{l}\text { Top Decile of } \\
\text { Commissions }\end{array}$ & $\begin{array}{c}\text { Ranking based on } \\
\text { Volume }\end{array}$ & $\begin{array}{c}\text { Ranking on } \\
\text { Commissions Paid }\end{array}$ \\
\hline Best Client $\times$ Liquidation Period & $\begin{array}{c}0.076 * * * \\
(3.795)\end{array}$ & $\begin{array}{c}0.059^{* * * *} \\
(4.698)\end{array}$ & $\begin{array}{c}0.065^{* * *} \\
(4.172)\end{array}$ & $\begin{array}{c}0.121 * * * \\
(3.437)\end{array}$ & $\begin{array}{c}0.113^{* * *} \\
(3.540)\end{array}$ \\
\hline Best Client & $\begin{array}{c}-0.045 * * * \\
(-3.290)\end{array}$ & $\begin{array}{c}-0.045 * * * \\
(-4.798)\end{array}$ & $\begin{array}{c}-0.056^{* * * *} \\
(-4.210)\end{array}$ & $\begin{array}{c}-0.122 * * * \\
(-3.785)\end{array}$ & $\begin{array}{c}-0.092 * * * \\
(-3.194)\end{array}$ \\
\hline Liquidation Period & $\begin{array}{c}0.009 \\
(0.679)\end{array}$ & $\begin{array}{c}0.002 \\
(0.157)\end{array}$ & $\begin{array}{c}0.001 \\
(0.102)\end{array}$ & $\begin{array}{c}-0.084 * * \\
(-2.052)\end{array}$ & $\begin{array}{r}-0.074 * * \\
(-1.997)\end{array}$ \\
\hline Time Fixed Effects & Yes & Yes & Yes & Yes & Yes \\
\hline Manager Fixed Effects & Yes & Yes & Yes & Yes & Yes \\
\hline Event Fixed Effects & Yes & Yes & Yes & Yes & Yes \\
\hline Stock Fixed Effects & Yes & Yes & Yes & Yes & Yes \\
\hline Broker Fixed Effects & Yes & Yes & Yes & Yes & Yes \\
\hline Observations & 65,762 & 65,762 & 65,762 & 36,705 & 36,705 \\
\hline R-squared & 0.155 & 0.155 & 0.156 & 0.179 & 0.179 \\
\hline
\end{tabular}

Panel B: Non-Hedge Funds Sample

\begin{tabular}{|c|c|c|c|c|c|}
\hline \multirow[t]{2}{*}{ Dependent variable } & \multicolumn{5}{|c|}{ Probability of Predation } \\
\hline & (1) & (2) & (3) & (4) & (5) \\
\hline Best clients proxy & Volume above $5 \%$ & Top Decile of Volume & $\begin{array}{l}\text { Top Decile of } \\
\text { Commissions }\end{array}$ & $\begin{array}{c}\text { Ranking based on } \\
\text { Volume }\end{array}$ & $\begin{array}{c}\text { Ranking on } \\
\text { Commissions Paid }\end{array}$ \\
\hline Best Client $\times$ Liquidation Period & $\begin{array}{c}0.015 \\
(0.757)\end{array}$ & $\begin{array}{l}0.026 * * \\
(2.524)\end{array}$ & $\begin{array}{l}0.024 * * \\
(2.450)\end{array}$ & $\begin{array}{c}0.029 \\
(1.346)\end{array}$ & $\begin{array}{c}0.021 \\
(1.140)\end{array}$ \\
\hline Best Client & $\begin{array}{l}-0.014 \\
(-0.879)\end{array}$ & $\begin{array}{l}-0.013 \\
(-0.995)\end{array}$ & $\begin{array}{l}-0.000 \\
(-0.011)\end{array}$ & $\begin{array}{l}-0.033 \\
(-1.117)\end{array}$ & $\begin{array}{l}-0.008 \\
(-0.290)\end{array}$ \\
\hline Liquidation Period & $\begin{array}{c}0.013 \\
(0.879)\end{array}$ & $\begin{array}{c}0.009 \\
(0.562)\end{array}$ & $\begin{array}{c}0.010 \\
(0.610)\end{array}$ & $\begin{array}{l}-0.024 \\
(-0.733)\end{array}$ & $\begin{array}{l}-0.016 \\
(-0.545)\end{array}$ \\
\hline Time Fixed Effects & Yes & Yes & Yes & Yes & Yes \\
\hline Manager Fixed Effects & Yes & Yes & Yes & Yes & Yes \\
\hline Event Fixed Effects & Yes & Yes & Yes & Yes & Yes \\
\hline Stock Fixed Effects & Yes & Yes & Yes & Yes & Yes \\
\hline Broker Fixed Effects & Yes & Yes & Yes & Yes & Yes \\
\hline Observations & 81,874 & 81,874 & 81,874 & 44,135 & 44,135 \\
\hline R-squared & 0.161 & 0.161 & 0.161 & 0.200 & 0.200 \\
\hline
\end{tabular}




\section{Table 11}

\section{Profitability of Predatory Trades}

The table reports results on the profitability of trades by predators around the fire sales events. We divide each event into a pre-fire sale period $[-10,-1]$ and a post-fire sale period $[0,9]$, where zero denotes the day on which the fire sale starts. We then compute the profitability of trades by manager $m$ on stock $j$ over the window $\pi=\left[t_{0}, t_{1}\right]$, which denotes either the pre or post fire sale period. Profitability is defined as

$$
\text { Profitability }_{m, j, \pi}=\left(\text { MarkToMarket }_{m, j, \pi}-\text { CashFlows }_{m, j, \pi}\right) / \text { Exposure }_{m, j, \pi} .
$$

Here, MarkToMarket ${ }_{m, j, \pi}$ is the marked-to-market dollar value of the position at time $t_{1}$, defined as the product of the share position cumulated from $t_{0}$ to $t_{1}$ with the market price of stock $j$ on day $t_{1}$. CashFlows $m, j, \pi$ is the dollar amount spent to build the position, i.e. the opposite of the dollar volume of each transaction in the stock (based on execution prices) from from $t_{0}$ to $t_{1}$. Exposur $e_{m, j, \pi}$ is the maximum dollar outlay over the relevant period, defined as $\max _{\mathrm{t} \in \pi} \mid$ CashFlows $_{m, j,\left[t_{0}, t\right]} \mid$. We compare the profitability (expressed in basis points) of trades by best clients of aware brokers to that of other managers, in the pre and post fire sale periods, using event-manager-stock level observations. Time and manager fixed-effects are added to the regression and standard errors are clustered at the manager level. T-stats are reported in parentheses. Asterisks denote significance levels $(* * *=1 \%, * *=5 \%, *=10 \%)$

\begin{tabular}{|c|c|c|c|c|c|}
\hline \multirow[t]{2}{*}{ Dependent variable } & \multicolumn{5}{|c|}{ Return on Capital (basis points) } \\
\hline & (1) & (2) & (3) & (4) & $(5)$ \\
\hline Best clients proxy & Volume above $5 \%$ & Top Decile of Volume & $\begin{array}{l}\text { Top Decile of } \\
\text { Commissions }\end{array}$ & $\begin{array}{c}\text { Ranking based on } \\
\text { Volume }\end{array}$ & $\begin{array}{l}\text { Ranking based on } \\
\text { Commissions Paid }\end{array}$ \\
\hline Best Client $\times$ Post & $\begin{array}{c}73.724 * * * \\
(2.682)\end{array}$ & $\begin{array}{c}48.204 * * \\
(2.447)\end{array}$ & $\begin{array}{c}47.076^{* *} \\
(2.245)\end{array}$ & $\begin{array}{c}71.270 * * \\
(2.083)\end{array}$ & $\begin{array}{c}74.517 * * \\
(2.248)\end{array}$ \\
\hline Best Client & $\begin{array}{c}-6.957 \\
(-0.583)\end{array}$ & $\begin{array}{c}-2.078 \\
(-0.188)\end{array}$ & $\begin{array}{l}-3.007 \\
(-0.306)\end{array}$ & $\begin{array}{l}-13.375 \\
(-0.903)\end{array}$ & $\begin{array}{c}-9.794 \\
(-0.707)\end{array}$ \\
\hline Post & $\begin{array}{l}-36.313 \\
(-1.004)\end{array}$ & $\begin{array}{l}-40.978 \\
(-1.132)\end{array}$ & $\begin{array}{l}-39.862 \\
(-1.098)\end{array}$ & $\begin{array}{c}-64.616^{*} \\
(-1.724)\end{array}$ & $\begin{array}{c}-64.903 * \\
(-1.721)\end{array}$ \\
\hline Time Fixed Effects & Yes & Yes & Yes & Yes & Yes \\
\hline Manager Fixed Effects & Yes & Yes & Yes & Yes & Yes \\
\hline Observations & 35,679 & 35,679 & 35,679 & 35,679 & 35,679 \\
\hline R-squared & 0.050 & 0.049 & 0.049 & 0.049 & 0.049 \\
\hline
\end{tabular}


Table 12

Price Impact and Broker Awareness

This table reports results on the price impact experienced by the fire sale originators. We construct the following price impact measures: (i) the execution shortfall based on the first placement price, (ii) the execution shortfall based on the first open price, (iii) the execution shortfall based on the first transaction price. We aggregate the measures taking their volume-weighted average across transactions and express them in basis points. In Panel A, we regress the price impact measures on a dummy indicating the presence of an aware broker at the event-stock level and the total volume of other managers (followers) relative to the stock market capitalization. We control for the originator volume relative to the stock market capitalization and the Amihud ratio of the stock, estimated on the previous six months. Time and stock fixed effects are added to the regression. In Panel Bb we repeat the exercise at the event-stock-broker-level and we add broker fixed effects. Continuos explanatory variables are standardized and standard errors are clustered by event. T-stats are reported in parentheses. Asterisks denote significance levels $(* * *=1 \%, * *=5 \%, *=10 \%)$

Panel A: Price Impact at the stock-level

\begin{tabular}{|c|c|c|c|}
\hline \multirow[t]{2}{*}{ Dependent variable } & \multicolumn{3}{|c|}{ Price Impact (basis points) } \\
\hline & (1) & (2) & (3) \\
\hline Benchmark Price & First Placement Price & Open Price & First Transaction Price \\
\hline \multirow[t]{2}{*}{ Aware Broker Dummy } & $34.922 * * *$ & $40.130 * * *$ & $22.079 * *$ \\
\hline & $(2.821)$ & $(2.937)$ & $(2.403)$ \\
\hline \multirow[t]{2}{*}{ Followers Volume } & $23.253 * * *$ & $23.796 * * *$ & 8.174 \\
\hline & $(2.728)$ & $(2.662)$ & $(1.632)$ \\
\hline \multirow[t]{2}{*}{ Generator Volume } & 8.062 & 10.259 & 1.141 \\
\hline & $(0.753)$ & $(0.863)$ & $(0.150)$ \\
\hline \multirow[t]{2}{*}{ Amihud Ratio } & -19.239 & -20.645 & -18.706 \\
\hline & $(-1.078)$ & $(-1.114)$ & $(-1.389)$ \\
\hline Time Fixed Effects & Yes & Yes & Yes \\
\hline Stock Fixed Effects & Yes & Yes & Yes \\
\hline Observations & 6,291 & 6,291 & 6,291 \\
\hline R-squared & 0.431 & 0.431 & 0.416 \\
\hline
\end{tabular}

Panel B: Price Impact at the broker-level

\begin{tabular}{|c|c|c|c|}
\hline \multirow[t]{2}{*}{ Dependent variable } & \multicolumn{3}{|c|}{ Price Impact (basis points) } \\
\hline & (1) & (2) & (3) \\
\hline Benchmark Price & First Placement Price & Open Price & First Transaction Price \\
\hline Aware Broker Dummy & $\begin{array}{c}25.808 * * * \\
(2.898)\end{array}$ & $\begin{array}{c}28.891 * * * \\
(2.865)\end{array}$ & $\begin{array}{c}18.871 * * * \\
(2.634)\end{array}$ \\
\hline Followers Volume & $\begin{array}{l}4.946 * * \\
(2.011)\end{array}$ & $\begin{array}{l}4.927 * \\
(1.797)\end{array}$ & $\begin{array}{c}2.510 \\
(1.278)\end{array}$ \\
\hline Generator Volume & $\begin{array}{c}21.853 * * * \\
(3.730)\end{array}$ & $\begin{array}{c}20.645^{* * *} * \\
(3.269)\end{array}$ & $\begin{array}{c}11.714 * * \\
(2.460)\end{array}$ \\
\hline Amihud Ratio & $\begin{array}{l}-12.153 \\
(-1.277)\end{array}$ & $\begin{array}{c}-6.693 \\
(-0.720)\end{array}$ & $\begin{array}{c}-8.296 \\
(-1.453)\end{array}$ \\
\hline Time Fixed Effects & Yes & Yes & Yes \\
\hline Stock Fixed Effects & Yes & Yes & Yes \\
\hline Broker Fixed Effects & Yes & Yes & Yes \\
\hline Observations & 28,265 & 28,265 & 28,265 \\
\hline R-squared & 0.323 & 0.338 & 0.265 \\
\hline
\end{tabular}




\section{Table 13}

Persistence of Broker Concentration

This table reports results on the concentration of brokers employed by asset managers in our sample. We construct three proxies of broker concentration: (i) the Herfindahl Index (HHI) of the trading volumes at the monthly frequency, (ii) the normalized Herfindahl Index (HHI) of the trading volumes at the monthly frequency and (iii) the number of brokers intermediating at least one trade of the manager in the given month. In Panel A, we regress each proxy on their one-month, six-months and one-year lags using observations at the manager-month level. In Panel B, we repeat the same exercise restricting to the sample to fire sale events. All the specifications include month fixed effects. Tstats are reported in parentheses. Asterisks denote significance levels $(* * *=1 \%, * *=5 \%, *=10 \%)$

Panel A: Unconditional Brokers Concentration

\begin{tabular}{|c|c|c|c|c|c|c|}
\hline Dependent Variable & HHI & HHI & Normalized HHI & Normalized HHI & Number of Brokers & Number of Brokers \\
\hline & (1) & (2) & (3) & (4) & (5) & (6) \\
\hline One Month Lag & $\begin{array}{c}0.592 * * * \\
(193.897)\end{array}$ & $\begin{array}{c}0.398 * * * \\
(104.549)\end{array}$ & $\begin{array}{c}0.388^{* * *} * \\
(111.338)\end{array}$ & $\begin{array}{l}0.279 * * * \\
(70.742)\end{array}$ & $\begin{array}{c}0.961 * * * \\
(908.650)\end{array}$ & $\begin{array}{c}0.756^{* * * *} \\
(270.680)\end{array}$ \\
\hline Six Months Lag & & $\begin{array}{l}0.220 * * * \\
(55.312)\end{array}$ & & $\begin{array}{l}0.179 * * * \\
(43.966)\end{array}$ & & $\begin{array}{l}0.144 * * * \\
(43.850)\end{array}$ \\
\hline One Year Lag & & $\begin{array}{l}0.172 * * * \\
(44.943)\end{array}$ & & $\begin{array}{l}0.156^{* * * *} \\
(39.187)\end{array}$ & & $\begin{array}{l}0.084 * * * \\
(30.395)\end{array}$ \\
\hline Month Fixed Effects & Yes & Yes & Yes & Yes & Yes & Yes \\
\hline Observations & 70,284 & 60,839 & 70,284 & 60,839 & 70,284 & 60,839 \\
\hline R-squared & 0.362 & 0.433 & 0.161 & 0.215 & 0.922 & 0.931 \\
\hline
\end{tabular}

Panel B: Brokers Concentration during Fire Sale Events

\begin{tabular}{|c|c|c|c|c|c|c|}
\hline Dependent Variable & HHI & HHI & Normalized HHI & Normalized HHI & Number of Brokers & Number of Brokers \\
\hline & (1) & (2) & (3) & (4) & (5) & (6) \\
\hline One Month Lag & $\begin{array}{l}0.260 * * * \\
(12.642)\end{array}$ & $\begin{array}{c}0.222 * * * \\
(9.749)\end{array}$ & $\begin{array}{l}0.203 \text { *** } \\
(10.445)\end{array}$ & $\begin{array}{c}0.170 * * * \\
(6.796)\end{array}$ & $\begin{array}{l}1.038^{* * *} \\
(55.184)\end{array}$ & $\begin{array}{l}1.011 * * * \\
(18.047)\end{array}$ \\
\hline Six Months Lag & & $\begin{array}{c}-0.001 \\
(-0.292)\end{array}$ & & $\begin{array}{c}-0.001 \\
(-0.227)\end{array}$ & & $\begin{array}{c}0.021 \\
(0.351)\end{array}$ \\
\hline One Year Lag & & $\begin{array}{l}0.027^{* *} \\
(2.180)\end{array}$ & & $\begin{array}{l}0.032 * \\
(1.813)\end{array}$ & & $\begin{array}{l}0.008 \\
(0.203)\end{array}$ \\
\hline Month Fixed Effects & Yes & Yes & Yes & Yes & Yes & Yes \\
\hline Observations & 322 & 284 & 322 & 284 & 322 & 284 \\
\hline R-squared & 0.654 & 0.734 & 0.590 & 0.670 & 0.958 & 0.957 \\
\hline
\end{tabular}




\section{Table 14}

Commissions Paid to Aware Brokers

The table presents evidence on the post-event increase of commissions paid by predators to aware brokers. For each month $t$ on a window starting two years before and ending two year after each fire sale event $e$, we define the average Commission_per_dollar $e_{e, m, b, t}$ paid by manager $m$ to broker $b$ as the ratio $\operatorname{Comm}_{e, m, b, t} / D V o l_{e, m, b, t}$, where $\operatorname{Comm}_{e, m, b, t}$ is the total amount in dollars paid in commissions by manager $m$ to broker $b$ during month $t$ and $D V o l_{e, m, b, t}$ is the total dollar volume traded by manager $m$ and intermediated by broker $b$ in that month. For each event, we consider brokers which are marked as Aware on at least one of the fire sale stocks and managers whose trades are intermediated by at least one of these broker in the ten trading days around the event. We then regress Commission_per_dollar $r_{e, m, b, t}$ on the interaction of the dummy variable Post $_{e, t}$, indicating the two years following the fire sale event, with each of our Best Clients proxies. We add event, manager, and brokers fixed-effects to the regression and we cluster standard errors by event-broker-manager to account for time-series autocorrelation in commissions paid. T-stats are reported in parentheses. Asterisks denote significance levels $(* * *=1 \%, * *=5 \%, *=10 \%)$

\begin{tabular}{|c|c|c|c|c|c|}
\hline \multirow[t]{2}{*}{ Dependent variable } & \multicolumn{5}{|c|}{ Commissions per dollar (basis points) } \\
\hline & (1) & (2) & (3) & (4) & (5) \\
\hline Best clients proxy & Volume above $5 \%$ & $\begin{array}{c}\text { Top Decile of } \\
\text { Volume }\end{array}$ & $\begin{array}{l}\text { Top Decile of } \\
\text { Commissions }\end{array}$ & $\begin{array}{c}\text { Ranking based on } \\
\text { Volume }\end{array}$ & $\begin{array}{c}\text { Ranking on } \\
\text { Commissions Paid }\end{array}$ \\
\hline Best Client $\times$ Post & $\begin{array}{l}0.553 * * * \\
(4.915)\end{array}$ & $\begin{array}{l}0.508 * * * \\
(5.567)\end{array}$ & $\begin{array}{l}0.377 * * * \\
(4.128)\end{array}$ & $\begin{array}{l}1.017 * * * \\
(8.534)\end{array}$ & $\begin{array}{l}0.906^{* * * *} \\
(7.628)\end{array}$ \\
\hline Best Client & $\begin{array}{l}-0.908 * * * \\
(-8.187)\end{array}$ & $\begin{array}{l}-0.947 * * * \\
(-9.514)\end{array}$ & $\begin{array}{l}-0.492 * * * \\
(-4.833)\end{array}$ & $\begin{array}{l}-4.127 * * * \\
(-12.830)\end{array}$ & $\begin{array}{c}-1.400 * * * \\
(-4.525)\end{array}$ \\
\hline Post & $\begin{array}{l}-0.682 * * * \\
(-12.711)\end{array}$ & $\begin{array}{l}-0.779 * * * \\
(-12.188)\end{array}$ & $\begin{array}{l}-0.739 * * * \\
(-11.616)\end{array}$ & $\begin{array}{l}-1.250 * * * \\
(-12.981)\end{array}$ & $\begin{array}{l}-1.169 * * * \\
(-12.339)\end{array}$ \\
\hline Event Fixed Effects & Yes & Yes & Yes & Yes & Yes \\
\hline Manager Fixed Effects & Yes & Yes & Yes & Yes & Yes \\
\hline Broker Fixed Effects & Yes & Yes & Yes & Yes & Yes \\
\hline Observations & 252,416 & 252,416 & 252,416 & 252,416 & 252,416 \\
\hline R-squared & 0.313 & 0.314 & 0.313 & 0.318 & 0.314 \\
\hline
\end{tabular}


Table 15

Hedging of Predatory Trades

The table presents evidence on predators hedging their short positions on the fire sale stocks with long positions on substitue stocks. We define substitute stocks those belonging to the same industry or industry group as the fire sale stock, as identified with the 4-digit Standard Industry Classification Code (SIC4) and by the SIC3, respectively. For each fire sale event, we consider ticket-level transactions of the best clients of aware brokers (as defined by our awareness measure and the five Best Client proxies) on all the stocks other than those involved in the fire sale, in a window of 5 trading days on each side of the start of the liquidation event. Fire sale originators are excluded from the sample. The dependent variable is a dummy variable Hedging $_{e, i, m}$ defined at the event-manager-stock level indicating buy trades of manager $m$ on stock $i$ such that manager $m$ sold stock $j$ during event $e$ and the stocks $i$ and $j$ are substitutes. The variable takes the value of zero for buy trades that are not in substitute stocks and for sell trades. We regress the dependent variable on the interaction of the aware dummy and the liquidation period dummy. In this case, the aware dummy is constructed at the manager-stock level and indicates whether the manager is a best client of an aware broker intermediating a fire sale in the same industry as that of the stock under consideration. T-stats are reported in parentheses. Asterisks denote significance levels $(* * *=1 \%, * *=5 \%, *=10 \%)$

\begin{tabular}{|c|c|c|c|c|c|c|}
\hline \multirow[t]{2}{*}{ Dependent variable } & \multicolumn{6}{|c|}{ Probability of Hedging } \\
\hline & (1) & (2) & (3) & (4) & (5) & (6) \\
\hline Best clients proxy & $\begin{array}{c}\text { Volume } \\
\text { above 5\% }\end{array}$ & $\begin{array}{c}\text { Top Decile of } \\
\text { Volume }\end{array}$ & $\begin{array}{l}\text { Top Decile of } \\
\text { Commissions }\end{array}$ & $\begin{array}{c}\text { Volume } \\
\text { above 5\% }\end{array}$ & $\begin{array}{c}\text { Top Decile of } \\
\text { Volume }\end{array}$ & $\begin{array}{l}\text { Top Decile of } \\
\text { Commissions }\end{array}$ \\
\hline Substitutes Proxy & \multicolumn{3}{|c|}{ Industry (4-digits SIC) } & \multicolumn{3}{|c|}{ Industry Group (3-digits SIC) } \\
\hline Aware $\times$ Liquidation Period & $\begin{array}{c}0.032 * * * \\
(4.911)\end{array}$ & $\begin{array}{l}0.031 \text { *** } \\
(5.296)\end{array}$ & $\begin{array}{c}0.033^{* * * *} \\
(5.528)\end{array}$ & $\begin{array}{c}0.034 * * * \\
(4.352)\end{array}$ & $\begin{array}{c}0.029 * * * * \\
(5.358)\end{array}$ & $\begin{array}{l}0.028 * * * \\
(5.742)\end{array}$ \\
\hline Aware & $\begin{array}{l}0.013 * * \\
(2.340)\end{array}$ & $\begin{array}{l}0.008 * \\
(1.808)\end{array}$ & $\begin{array}{c}0.006 \\
(1.388)\end{array}$ & $\begin{array}{c}0.021 * * * \\
(3.236)\end{array}$ & $\begin{array}{c}0.020^{* * * *} \\
(3.749)\end{array}$ & $\begin{array}{l}0.020 * * * \\
(3.443)\end{array}$ \\
\hline Liquidation Period & $\begin{array}{c}0.024 * * * \\
(4.855)\end{array}$ & $\begin{array}{c}0.023 * * * \\
(4.436)\end{array}$ & $\begin{array}{c}0.022 * * * \\
(4.420)\end{array}$ & $\begin{array}{c}0.029 * * * \\
(6.069)\end{array}$ & $\begin{array}{c}0.029 * * * \\
(6.576)\end{array}$ & $\begin{array}{l}0.029 * * * \\
(7.205)\end{array}$ \\
\hline Time Fixed Effects & Yes & Yes & Yes & Yes & Yes & Yes \\
\hline Manager Fixed Effects & Yes & Yes & Yes & Yes & Yes & Yes \\
\hline Event Fixed Effects & Yes & Yes & Yes & Yes & Yes & Yes \\
\hline Stock Fixed Effects & Yes & Yes & Yes & Yes & Yes & Yes \\
\hline Broker Fixed Effects & Yes & Yes & Yes & Yes & Yes & Yes \\
\hline Observations & $1,121,416$ & $1,121,416$ & $1,121,416$ & $2,424,354$ & $2,424,354$ & $2,424,354$ \\
\hline R-squared & 0.087 & 0.087 & 0.086 & 0.082 & 0.082 & 0.082 \\
\hline
\end{tabular}




\section{Brokers and Order Flow Leakage: Evidence from Fire Sales}

Andrea Barbon Marco Di Maggio Francesco Franzoni Augustin Landier

INTERNET APPENDIX 


\section{Table A1}

\section{Robustness: Broker Awareness Threshold}

The table reports results on the likelihood of a broker to attract predatory trades. The regressions are run at the ticketlevel, excluding trades by managers originating the fire-sale of interest or another overlapping fire-sale. The independent variable Aware is a dummy, defined at the event-broker-stock-day level, indicating that the broker is aware of the fire sale happening on the traded stock on that day. Precisely, this means that for broker $B$, stock $j$ on day $t$ the variable $A w a B r o t=0.5 \times A w a E v_{t}^{B j}\left(1+A w a S t o_{t}^{B j}\right)$ is above a given threshold. We test the robustness of the main results reported in Table 2 with respect different levels of the threshold, ranging from $1 \%$ to $30 \%$. Here $A w a S t o_{t}^{B j}$ is the stock-level awareness, defined as the ratio between the turnover intermediated by $B$ on stock $j$ up to day $t$ and the total turnover on stock $i$ up to day $t$ (over all the active brokers). $A w a E v_{t}^{B}$ is the event-level awareness, i.e. the ratio between the turnover intermediated by $B$ on all the fire sale stocks up to day $t$ and the total turnover on all the fire sale stocks up to that day (over all the active brokers). In Panel A, the dependent variable is a dummy indicating predation, i.e. it takes value one when the trade is in the same direction of the volume by the liquidating fund for that stock on that day (i.e. it is a sell trade), while it equals zero if the trade is in the opposite direction (i.e. a buy trade), or if the liquidating fund is not trading that stock on that particular day. In Panel B, we weight the above described dependent variable by the volume of the trade as a fraction of market capitalization, standardized. Standard errors are clustered at the broker level. T-stats are reported in parentheses. Asterisks denote significance levels $(* * *=1 \%, * *=5 \%, *=10 \%)$.

Panel A: Probability of Predation

\begin{tabular}{|c|c|c|c|c|c|c|c|c|c|c|c|c|c|c|}
\hline \multirow[t]{2}{*}{ Dependent Variable } & \multicolumn{14}{|c|}{ Probability of Predation } \\
\hline & (1) & (2) & (3) & (4) & (5) & (6) & (7) & (6) & (7) & (8) & (9) & (10) & (11) & (12) \\
\hline Awareness Threshold & $1 \%$ & $5 \%$ & $10 \%$ & $15 \%$ & $20 \%$ & $25 \%$ & $30 \%$ & $1 \%$ & $5 \%$ & $10 \%$ & $15 \%$ & $20 \%$ & $25 \%$ & $30 \%$ \\
\hline Aware & $\begin{array}{c}0.074 * * * \\
(4.634)\end{array}$ & $\begin{array}{c}0.074 * * * \\
(4.634)\end{array}$ & $\begin{array}{c}0.060 * * * \\
(4.642)\end{array}$ & $\begin{array}{c}0.074 * * * \\
(3.318)\end{array}$ & $\begin{array}{l}0.070^{* * *} \\
(2.556)\end{array}$ & $\begin{array}{l}0.065^{* *} \\
(2.212)\end{array}$ & $\begin{array}{l}0.083^{* * *} \\
(2.293)\end{array}$ & $\begin{array}{c}0.060^{\text {**** }} \\
(4.642)\end{array}$ & $\begin{array}{c}0.060^{* * *} \\
(4.642)\end{array}$ & $\begin{array}{c}0.060^{* * * *} \\
(4.642)\end{array}$ & $\begin{array}{c}0.055^{* * * *} \\
(2.953)\end{array}$ & $\begin{array}{l}0.047^{* *} \\
(2.028)\end{array}$ & $\begin{array}{c}0.037 \\
(1.473)\end{array}$ & $\begin{array}{c}0.044 \\
(1.408)\end{array}$ \\
\hline Time Fixed Effects & Yes & Yes & Yes & Yes & Yes & Yes & Yes & Yes & Yes & Yes & Yes & Yes & Yes & Yes \\
\hline Manager Fixed Effects & Yes & Yes & Yes & Yes & Yes & Yes & Yes & Yes & Yes & Yes & Yes & Yes & Yes & Yes \\
\hline Broker Fixed Effects & Yes & Yes & Yes & Yes & Yes & Yes & Yes & Yes & Yes & Yes & Yes & Yes & Yes & Yes \\
\hline Event Fixed Effects & & & & & & & & Yes & Yes & Yes & Yes & Yes & Yes & Yes \\
\hline Observations & 496,555 & 496,555 & 496,555 & 496,555 & 496,555 & 496,555 & 496,555 & 496,555 & 496,555 & 496,555 & 496,555 & 496,555 & 496,555 & 496,555 \\
\hline R-squared & 0.107 & 0.107 & 0.107 & 0.107 & 0.107 & 0.107 & 0.106 & 0.120 & 0.120 & 0.120 & 0.120 & 0.120 & 0.120 & 0.120 \\
\hline
\end{tabular}

Panel B: Volume of Predatory Trades

\begin{tabular}{|c|c|c|c|c|c|c|c|c|c|c|c|c|c|c|}
\hline \multirow[t]{2}{*}{ Dependent Variable } & \multicolumn{14}{|c|}{ Volume of Predatory Trades } \\
\hline & (1) & (2) & (3) & (4) & (5) & (6) & (7) & (6) & (7) & (8) & (9) & (10) & (11) & (12) \\
\hline Awareness Threshold & $1 \%$ & $5 \%$ & $10 \%$ & $15 \%$ & $20 \%$ & $25 \%$ & $30 \%$ & $1 \%$ & $5 \%$ & $10 \%$ & $15 \%$ & $20 \%$ & $25 \%$ & $30 \%$ \\
\hline Aware & $\begin{array}{l}0.166^{* *} \\
(2.508)\end{array}$ & $\begin{array}{l}0.166^{* * *} \\
(2.508)\end{array}$ & $\begin{array}{c}0.140 * * * \\
(3.811)\end{array}$ & $\begin{array}{l}0.204 * \\
(1.898)\end{array}$ & $\begin{array}{c}0.222 \\
(1.552)\end{array}$ & $\begin{array}{l}0.257^{*} \\
(1.656)\end{array}$ & $\begin{array}{c}0.321 \\
(1.508)\end{array}$ & $\begin{array}{c}0.140^{* * * *} \\
(3.811)\end{array}$ & $\begin{array}{c}0.140 * * * \\
(3.811)\end{array}$ & $\begin{array}{c}0.140 * * * \\
(3.811)\end{array}$ & $\begin{array}{c}0.167 * * * \\
(2.736)\end{array}$ & $\begin{array}{l}0.178 * \\
(1.950)\end{array}$ & $\begin{array}{l}0.206 * * \\
(2.169)\end{array}$ & $\begin{array}{l}0.248^{*} \\
(1.854)\end{array}$ \\
\hline Time Fixed Effects & Yes & Yes & Yes & Yes & Yes & Yes & Yes & Yes & Yes & Yes & Yes & Yes & Yes & Yes \\
\hline Manager Fixed Effects & Yes & Yes & Yes & Yes & Yes & Yes & Yes & Yes & Yes & Yes & Yes & Yes & Yes & Yes \\
\hline Broker Fixed Effects & Yes & Yes & Yes & Yes & Yes & Yes & Yes & Yes & Yes & Yes & Yes & Yes & Yes & Yes \\
\hline Event Fixed Effects & & & & & & & & Yes & Yes & Yes & Yes & Yes & Yes & Yes \\
\hline Observations & 489,148 & 489,148 & 489,148 & 489,148 & 489,148 & 489,148 & 489,148 & 489,148 & 489,148 & 489,148 & 489,148 & 489,148 & 489,148 & 489,148 \\
\hline $\mathrm{R}$-squared & 0.032 & 0.032 & 0.032 & 0.032 & 0.032 & 0.032 & 0.032 & 0.037 & 0.037 & 0.037 & 0.037 & 0.037 & 0.037 & 0.037 \\
\hline
\end{tabular}


Table A2

Robustness: Broker-Manager Fixed Effects

The table presents evidence of the effect of broker-client relationship strength on the probability of predatory behavior. The regressions are run at the ticket-level, excluding trades by managers originating the fire-sale of interest or another overlapping fire-sale. In all specifications the dependent variable is a dummy indicating predation, i.e. it takes value one when the trade is in the same direction of the volume by the fire-sale originator for that stock on that day, while it equals zero if the trade is in the opposite direction or if the originator is not trading that stock on that particular day. We regress the dependent variable on a dummy indicating if the manager is among the best clients of the broker intermediating the transcation, a dummy indicating the first 5 days of the fire sale, and the interaction of the two dummies. This dummy equals zero for the five days before the fire sale. We consider all trades on stock $j$ intermediated by brokers that eventually become aware that the stock is subject to fire sale pressure, i.e. brokers $B$ for which

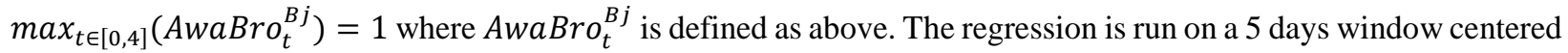
at the beginning of the fire sale $(\mathrm{t}=0)$, defined as the first day in which our liquidation measure crosses the threshold. We also include Broker $\times$ Manager and Broker $\times$ Originator fixed effects. Standard errors are clustered by event-stockmanager and T-stats are reported in parentheses. Asterisks denote significance levels $(* * *=1 \%, * *=5 \%, *=10 \%)$

\begin{tabular}{|c|c|c|c|c|c|}
\hline \multirow[t]{2}{*}{ Dependent variable } & \multicolumn{5}{|c|}{ Probability of Predation } \\
\hline & (1) & (2) & (3) & (4) & (5) \\
\hline Best clients proxy & Volume above 5\% & Top Decile of Volume & $\begin{array}{l}\text { Top Decile of } \\
\text { Commissions }\end{array}$ & $\begin{array}{c}\text { Ranking based on } \\
\text { Volume }\end{array}$ & $\begin{array}{l}\text { Ranking based on } \\
\text { Commissions Paid }\end{array}$ \\
\hline Best Client $\times$ Liquidation Period & $\begin{array}{c}0.031 * * * \\
(5.478)\end{array}$ & $\begin{array}{c}0.020 * * * \\
(5.768)\end{array}$ & $\begin{array}{c}0.022 * * * \\
(6.284)\end{array}$ & $\begin{array}{c}0.019 * * * \\
(3.450)\end{array}$ & $\begin{array}{c}0.021 * * * \\
(4.043)\end{array}$ \\
\hline Best Client & $\begin{array}{c}-0.033 \\
(-1.182)\end{array}$ & $\begin{array}{c}-0.038 * * \\
(-2.162)\end{array}$ & $\begin{array}{c}0.006 \\
(0.484)\end{array}$ & $\begin{array}{c}-0.071 * * * \\
(-3.047)\end{array}$ & $\begin{array}{c}-0.067 * * * \\
(-2.778)\end{array}$ \\
\hline Liquidation Period & $\begin{array}{l}0.010^{*} \\
(1.756)\end{array}$ & $\begin{array}{c}0.007 \\
(1.366)\end{array}$ & $\begin{array}{c}0.007 \\
(1.353)\end{array}$ & $\begin{array}{c}0.004 \\
(0.695)\end{array}$ & $\begin{array}{c}0.003 \\
(0.592)\end{array}$ \\
\hline Time Fixed Effects & Yes & Yes & Yes & Yes & Yes \\
\hline Manager Fixed Effects & Yes & Yes & Yes & Yes & Yes \\
\hline Event Fixed Effects & Yes & Yes & Yes & Yes & Yes \\
\hline Stock Fixed Effects & Yes & Yes & Yes & Yes & Yes \\
\hline Broker Fixed Effects & Yes & Yes & Yes & Yes & Yes \\
\hline Broker-Manager Fixed Effects & Yes & Yes & Yes & Yes & Yes \\
\hline Broker-Originator Effects & Yes & Yes & Yes & Yes & Yes \\
\hline Observations & 147,665 & 147,665 & 147,665 & 147,665 & 147,665 \\
\hline R-squared & 0.293 & 0.293 & 0.293 & 0.292 & 0.292 \\
\hline
\end{tabular}


Table A3

Evidence of Predation from Trading Volume

The table presents results on the likelihood that managers engage in predation trading in the same direction of the firesale originator, weighted by the trading volume. The regressions are run at the ticket-level, excluding trades by managers originating the fire-sale of interest or another overlapping fire-sale. In all specifications the dependent variable is the product of the predation dummy defined in Table 4 multiplied by the volume of the transaction as a fraction of the market capitalization of the traded stock. The independent variables are the same as in the previous specifications. The regression is run on a window of five days on each side of the beginning of the fire sale $(t=0)$, defined as the first day in which our liquidation measure crosses the threshold. In specifications of Panel B we repeat the exercise excluding the NBER recession periods and stocks experiencing negative fundamental news, high short interest or negative momentum. We include manager, broker, stock, day, and event fixed effects and we cluster standard errors at the event-stock-manager level. T-stats are reported in parentheses. Asterisks denote significance levels $(* * *=1 \%, * *=5 \%, *=10 \%)$

Panel A: Full Sample

\begin{tabular}{|c|c|c|c|c|c|}
\hline \multirow[t]{2}{*}{ Dependent variable } & \multicolumn{5}{|c|}{ Probability of Predation } \\
\hline & (1) & (2) & (3) & (4) & (5) \\
\hline Best clients proxy & Volume above 5\% & Top Decile of Volume & $\begin{array}{l}\text { Top Decile of } \\
\text { Commissions }\end{array}$ & $\begin{array}{l}\text { Ranking based on } \\
\text { Volume }\end{array}$ & $\begin{array}{l}\text { Ranking based on } \\
\text { Commissions Paid }\end{array}$ \\
\hline Best Client $\times$ Liquidation Period & $\begin{array}{c}0.084 * * * \\
(3.365)\end{array}$ & $\begin{array}{c}0.056 * * * \\
(3.897)\end{array}$ & $\begin{array}{c}0.052 * * * \\
(3.666)\end{array}$ & $\begin{array}{c}0.059 * * * \\
(3.185)\end{array}$ & $\begin{array}{c}0.067 * * * \\
(3.767)\end{array}$ \\
\hline Best Client & $\begin{array}{c}-0.122 * * * \\
(-2.601)\end{array}$ & $\begin{array}{l}-0.071 * * * \\
(-2.600)\end{array}$ & $\begin{array}{c}-0.081 * * * \\
(-2.814)\end{array}$ & $\begin{array}{l}-0.052 \\
(-0.999)\end{array}$ & $\begin{array}{l}-0.049 \\
(-0.901)\end{array}$ \\
\hline Liquidation Period & $\begin{array}{l}0.044 * * \\
(2.054)\end{array}$ & $\begin{array}{l}0.038^{*} \\
(1.780)\end{array}$ & $\begin{array}{l}0.040^{*} \\
(1.847)\end{array}$ & $\begin{array}{c}0.008 \\
(0.348)\end{array}$ & $\begin{array}{c}0.005 \\
(0.206)\end{array}$ \\
\hline Time Fixed Effects & Yes & Yes & Yes & Yes & Yes \\
\hline Manager Fixed Effects & Yes & Yes & Yes & Yes & Yes \\
\hline Event Fixed Effects & Yes & Yes & Yes & Yes & Yes \\
\hline Stock Fixed Effects & Yes & Yes & Yes & Yes & Yes \\
\hline Broker Fixed Effects & Yes & Yes & Yes & Yes & Yes \\
\hline Observations & 143,693 & 143,693 & 143,693 & 143,693 & 143,693 \\
\hline R-squared & 0.321 & 0.321 & 0.321 & 0.321 & 0.321 \\
\hline \multicolumn{6}{|c|}{ Panel B: Excluding All Negative Events or Stocks } \\
\hline Dependent variable & \multicolumn{5}{|c|}{ Probability of Predation } \\
\hline Best clients proxy & $\begin{array}{c}\text { (1) } \\
\text { Volume above 5\% }\end{array}$ & $\begin{array}{c}\text { (2) } \\
\text { Top Decile of Volume }\end{array}$ & $\begin{array}{c}\text { (3) } \\
\text { Top Decile of } \\
\text { Commissions }\end{array}$ & $\begin{array}{c}\text { (4) } \\
\text { Ranking based on } \\
\text { Volume }\end{array}$ & $\begin{array}{c}\text { (5) } \\
\text { Ranking based on } \\
\text { Commissions Paid }\end{array}$ \\
\hline Best Client $\times$ Liquidation Period & $\begin{array}{l}0.109 * * * \\
(3.599)\end{array}$ & $\begin{array}{c}0.063 * * * \\
(4.013)\end{array}$ & $\begin{array}{c}0.056^{* * * *} \\
(3.492)\end{array}$ & $\begin{array}{l}0.036^{*} \\
(1.716)\end{array}$ & $\begin{array}{l}0.043 * * \\
(2.165)\end{array}$ \\
\hline Best Client & $\begin{array}{l}-0.120 * * * \\
(-2.622)\end{array}$ & $\begin{array}{c}-0.077 * * * \\
(-3.282)\end{array}$ & $\begin{array}{l}-0.057 * * \\
(-2.263)\end{array}$ & $\begin{array}{l}-0.033 \\
(-0.516)\end{array}$ & $\begin{array}{c}-0.033 \\
(-0.525)\end{array}$ \\
\hline Liquidation Period & $\begin{array}{c}0.026 \\
(0.998)\end{array}$ & $\begin{array}{c}0.021 \\
(0.797)\end{array}$ & $\begin{array}{c}0.023 \\
(0.876)\end{array}$ & $\begin{array}{c}0.007 \\
(0.262)\end{array}$ & $\begin{array}{c}0.004 \\
(0.151)\end{array}$ \\
\hline Time Fixed Effects & Yes & Yes & Yes & Yes & Yes \\
\hline Manager Fixed Effects & Yes & Yes & Yes & Yes & Yes \\
\hline Event Fixed Effects & Yes & Yes & Yes & Yes & Yes \\
\hline Stock Fixed Effects & Yes & Yes & Yes & Yes & Yes \\
\hline Broker Fixed Effects & Yes & Yes & Yes & Yes & Yes \\
\hline Observations & 103,715 & 103,715 & 103,715 & 103,715 & 103,715 \\
\hline R-squared & 0.373 & 0.373 & 0.373 & 0.373 & 0.373 \\
\hline
\end{tabular}


Table A4

Commissions Paid to Aware Brokers

The table presents evidence on the post-event increase of commissions paid by predators to aware brokers. For each month $t$ on a window of two years around each fire sale event $e$, we define the average Commission_per_dollar $r_{e, m, b, t}$ paid by manager $m$ to broker $b$ as the ratio $\operatorname{Comm}_{e, m, b, t} / D V o l_{e, m, b, t}$ where ratio $\operatorname{Comm}_{e, m, b, t}$ is the total amount in dollars paid in commissions by manager $m$ to broker $b$ during month $t$ and $D V o l_{e, m, b, t}$ is the total dollar volume traded by manager $m$ and intermediated by broker $b$ in that month. For each event, we consider brokers which are marked as Aware on at least one of the fire sale stocks and managers whose trades are intermediated by at least one of these broker in the ten trading days around the event. We then regress Commission_per_dollar ${ }_{e, m, b, t}$ on the interaction of the dummy variable Post $_{e, t}$, indicating the two years following the fire sale event, with each of our Best Clients proxies. In Panel A we look at the clients that are more likely to predate on that stock in that event, which we identify as those that are in the top half of the distribution of profitability in the ten-day window after the event. In Panel B we run the same analysis focusing on brokers' clients that trade in the same direction as the liquidating fund during the liquidation periods. We add event, manager, and brokers fixed-effects to the regression and we cluster standard errors by event-broker-manager to account for time-series autocorrelation in commissions paid. T-stats are reported in parentheses. Asterisks denote significance levels $(* * *=1 \%, * *=5 \%, *=10 \%)$

\section{Panel A: Highest Predatory Profits}

\begin{tabular}{|c|c|c|c|c|c|}
\hline \multirow[t]{2}{*}{ Dependent variable } & \multicolumn{5}{|c|}{ Commissions per dollar (basis points) } \\
\hline & (1) & (2) & (3) & (4) & (5) \\
\hline Best clients proxy & Volume above $5 \%$ & $\begin{array}{c}\text { Top Decile of } \\
\text { Volume }\end{array}$ & $\begin{array}{l}\text { Top Decile of } \\
\text { Commissions }\end{array}$ & $\begin{array}{c}\text { Ranking based on } \\
\text { Volume }\end{array}$ & $\begin{array}{c}\text { Ranking on } \\
\text { Commissions Paid }\end{array}$ \\
\hline Best Client $\times$ Post & $\begin{array}{l}0.743 * * * \\
(4.021)\end{array}$ & $\begin{array}{l}0.360 * * \\
(2.056)\end{array}$ & $\begin{array}{l}0.297^{*} \\
(1.838)\end{array}$ & $\begin{array}{l}0.558 * * * \\
(3.201)\end{array}$ & $\begin{array}{l}0.515 * * * \\
(2.932)\end{array}$ \\
\hline Best Client & $\begin{array}{l}-0.649 * * * \\
(-2.772)\end{array}$ & $\begin{array}{c}-0.342 \\
(-1.435)\end{array}$ & $\begin{array}{c}-0.233 \\
(-0.956)\end{array}$ & $\begin{array}{l}-0.545^{* * * *} \\
(-2.883)\end{array}$ & $\begin{array}{l}-0.440 * * \\
(-2.106)\end{array}$ \\
\hline Post & $\begin{array}{l}-0.635 * * * \\
(-6.325)\end{array}$ & $\begin{array}{l}-0.658 * * * \\
(-5.971)\end{array}$ & $\begin{array}{l}-0.642 * * * \\
(-5.830)\end{array}$ & $\begin{array}{l}-0.768 * * * \\
(-5.970)\end{array}$ & $\begin{array}{l}-0.752 * * * \\
(-5.862)\end{array}$ \\
\hline Event Fixed Effects & Yes & Yes & Yes & Yes & Yes \\
\hline Manager Fixed Effects & Yes & Yes & Yes & Yes & Yes \\
\hline Broker Fixed Effects & Yes & Yes & Yes & Yes & Yes \\
\hline Observations & 121,749 & 121,749 & 121,749 & 121,749 & 121,749 \\
\hline R-squared & 0.408 & 0.408 & 0.408 & 0.408 & 0.408 \\
\hline \multicolumn{6}{|c|}{ Panel B: Predators Only } \\
\hline Dependent variable & \multicolumn{5}{|c|}{ Commissions per dollar (basis points) } \\
\hline & (1) & (2) & (3) & (4) & (5) \\
\hline Best clients proxy & Volume above $5 \%$ & $\begin{array}{c}\text { Top Decile of } \\
\text { Volume }\end{array}$ & $\begin{array}{l}\text { Top Decile of } \\
\text { Commissions }\end{array}$ & $\begin{array}{c}\text { Ranking based on } \\
\text { Volume }\end{array}$ & $\begin{array}{c}\text { Ranking on } \\
\text { Commissions Paid }\end{array}$ \\
\hline Best Client $\times$ Post & $\begin{array}{l}0.627 * * * \\
(4.068)\end{array}$ & $\begin{array}{l}0.494 * * * \\
(2.938)\end{array}$ & $\begin{array}{l}0.446 * * * \\
(2.712)\end{array}$ & $\begin{array}{l}0.972 * * * \\
(3.834)\end{array}$ & $\begin{array}{l}0.922 * * * \\
(3.651)\end{array}$ \\
\hline Best Client & $\begin{array}{l}-0.480 * * * \\
(-3.568)\end{array}$ & $\begin{array}{l}-0.832 * * * \\
(-2.821)\end{array}$ & $\begin{array}{l}-0.334 \\
(-1.097)\end{array}$ & $\begin{array}{l}-1.604 \\
(-0.897)\end{array}$ & $\begin{array}{c}1.075 \\
(0.650)\end{array}$ \\
\hline Post & $\begin{array}{l}-0.766 * * * \\
(-6.960)\end{array}$ & $\begin{array}{l}-0.870 * * * \\
(-6.194)\end{array}$ & $\begin{array}{l}-0.845^{* * *} \\
(-6.089)\end{array}$ & $\begin{array}{l}-1.270 * * * \\
(-5.710)\end{array}$ & $\begin{array}{l}-1.233 * * * \\
(-5.618)\end{array}$ \\
\hline Event Fixed Effects & Yes & Yes & Yes & Yes & Yes \\
\hline Manager Fixed Effects & Yes & Yes & Yes & Yes & Yes \\
\hline Broker Fixed Effects & Yes & Yes & Yes & Yes & Yes \\
\hline Observations & 141,685 & 141,685 & 141,685 & 141,685 & 141,685 \\
\hline R-squared & 0.410 & 0.410 & 0.410 & 0.411 & 0.411 \\
\hline
\end{tabular}

